"Bibliotheca Botanica," illustrated by eleven fine plates, by Herr G. Karsten. Herr Karsten points out that, in addition to the obvious mechanical function of these roots, serving as a supporting organ to attach the trees more firmly to the very loose soil in which they grow-this is especially observable in Rhizophora mangle-there is another important function performed by them, at least in a large number of the trees which make up the mangrove-vegetation, though I do not recollect that Avicennia nivea is especially mentioned. In the species examined by Karsten, these aërial roots possess very large intercellular spaces, which serve to promote the interchange of gases ; and he considers it unquestionable that their chief function is to assist respiration. He therefore proposes for them the term "pneumatophores." It would be interesting to examine the structure of the trees at the Botanic Garden in this respect. All mangrove-trees also contain large quantities of tannin, which is probably serviceable in preventing rotting.

August I. ALFRED W. BENNETT.

\section{The Tasman Sea.}

I SEND you the inclosed copy of a letter from the Secretary of the Admiralty, in case you should consider the matter of sufficient interest for notice in your columns.

A. Liversidge, Permanent Hon. Sec. Australasian Association for the Advancement

The University, Sydney, July 4. of Science.

Admiralty, May 19, I891.

SIR,--With reference to your letter of March 17 , forwarding copy of a resolution passed by the Australasian Association for the Advancement of Science at the meeting held at Christchurch, New Zealand, that the name of Tasman Sea should be given to the sea between New Zealand and the islands of the north-west of New Zealand on the one hand and Australia and Tasmania on the other, I am commanded by my Lords Commissioners of the Admiralty to acquaint you that the name will be inserted in Admiralty charts and other publications.

$$
\text { I am, Sir, }
$$

$$
\text { Your obedient servant, }
$$
Evan MACGREgor.

To Prof. Liversidge, M.A., F.R.S.,

The University, Sydney.

\section{Reduplication of Seasonal Growth.}

LAST summer I sent you a note on the occurrence of appleblossoms and the blossoms of the mountain ash in July. Before me now, as I write, is a simple but elegant bouquet containing a beautiful and fragrant corymb of the latter tree in full flower, side by side with one of the ripe scarlet fruit, which the blackbirds have begun to devour. These were cut from one and the self-same tree this morring at the top of my garden; while from an adjoining tree was gathered a twig carrying four pinnate leaves from which all the chlorophyll has disappeared; the phenomena which mark the beginning and the end of the season thus appearing side by side. These trees grows on the Upper Bagshot Sands, and I have no doubt that this reduplication of seasonal growth is due to the later rains developing some centres of flowering energy in the plant, which had remained dormant during the spring owing to deficiency of moisture and warmth.

Wellington College, Berks, August I 7 .

A. IRVING.

\section{Rain-gauges.}

I HAVE been using the ordinary Symonds pattern rain-gauge, but find that the percentage of rain collected varies in proportion to the strength of the wind; when this is moderately strong, almost the whole of the rain passes across the top. striking and being retained by vertical surfaces only.

The present method of estimating the rainfall is far from being either correct or uniform, and I should like to ascertain if any gauge has been made with a correctly-proportioned inverted cone, which will collect and compensate for side drive; and, if so, what are the correct proportions. It would appear that either this, or a funnel mounted on gimbals and balanced to face the wind at the correct angle, must be the only correct method to ascertain the actual rainfall. The present apparatus would appear to be crude, untrustworthy, and incapable under any conditions in practice of giving results which are at all trus:worthy.

Grappenhall House, Grappenhall, near Warrington, August 17 .

\section{THE BRITISH ASSOCIATION.}

(FROM OUR CORRESPONDENT.)

CARDIFF, Wednesday Morning.

THE preparations of the Local Committee are now in an advanced state, and members of the Association are beginning to arrive in considerable numbers.

A change has been made in the position of the Reception Room, which is now located entirely in the Drill Hall, the Town Hall having had to be abandoned for that purpose owing to the impossibility of making adequate provision for the accommodation of the large number of guests expected. The Drill Hall is a large building, and has been divided into two parts by a screen, which also serves the purpose of a notice-board. On the entrance side are the offices for various purposes, post and excursions; and at a central oval counter, all other requirements relating to tickets, reserved seats, publications, and lodgings are attended to by a numerous staff of clerks.

Beyond the screen the hall has been fitted up as a drawing-room, and from this lead off smaller rooms for ladies, the press, and smokers. Separated from the drawing-room by a passage is the gun-room, from which everything has been removed, and tables laid down so as to convert it into a dining-room.

The President's address will be given in the Park Hall, this evening, and for the half-hour of waiting before the business commences Mr. T. E. Aylward will give a recital upon the fine organ in that hall. It is understood that Lord Bute, as Mayor of Cardiff, will at the outset welcome the Association in the name of the town of Cardiff.

The conversazioni will also be given in the same hall, and from 8.30 to 9 p.m., Lord Bute, as Chairman of the Local Committee, accompanied by Lady Bute, will receive the guests. At 9.30 p.m. an exhibition of views will be given by the lime-light, amongst them some fine ones, by Mr. M. Stirrup, of the limestone region of Languedoc. Amongst other attractions will be taking impressions of finger-tips, by Sergeant Randall (Mr. F. Galton's assistant); a model of the moon, shown by the Astronomer-Royal of Scotland; drawings in black and white of the Himalayas, by Col. Tanner; a collection of old local maps and atlases, by Mr. O. H. Jones; the Eisteddfod concert given at Swansea transmitted by telephone, by Mr. Gavey; and numerous other objects of interest.

Arrangements have been made for military and vocal music.

No alteration has been made in the Section rooms from that mentioned in our former article.

The publications of the Local Committee are ready for distribution, and comprise the local hand-book of 240 pages dealing with the archæology of the land of Morgan, the education, botany, geology, industries, and topography of Cardiff ; the excursions-guide containing a map of the district on a scale of four miles to the inch, and two maps on a larger scale, one of the Bute Docks, and the other of the Barry Dock. The excursions number twenty in all --twelve are arranged for Saturday, the $22 \mathrm{nd}$, and eight for Thursday, the 27 th ; and moderately detailed descriptions of each are given in the guide to the excursions.

The local programme, and the list of lodgings and hotels, are the remaining publications of the Committee. The total number of members of all classes who have taken out tickets for the meeting was, at 6 p.m. yesterday, over 900 .

The President's address is as follows :-

NO. I I 38 , vOL. 44] 
Inaugural Adiress by William Huggins, Esq., D.C.L. (Oxon.), Ll.D. (Cantab., Enin., et Dubl), Ph.D. (Lugd. Bat.), F.R.S., F.R.A.S., Hon. F.R.S.E., \&C. Corresponisant de L'Institut de France, President.

IT is now many years since this Association has done honour to the science of Astronomy in the selection of its President.

Since Sir George Airy occupied the chair in 1851 , and the late Lord Wrottesley nine years later, in 1860 , other sciences have been represented by the distinguished men who have presided over your meetings.

The very remartable discoveries in our knowledge of the heavens which have taken place during this period of thirty years-one of amazing and ever-increasing activity in all branches of science--have not passed unnoticed in the addresses of your successive Presidents; still it seems to me fitting that I should speak to you to-night chiefly of those newer methods of astronomical research which have led to those discoveries, and which have become possible by the introduction since 1860 into the observatory of the spectroscope and the modern photographic plate.

In $\mathrm{I} 866 \mathrm{I}$ had the honour of bringing before this Association, at one of the evening lectures, an account of the first fruits of the novel and unexpected advances in our knowledge of the celestial bodies which followed rapidly upon Kirchhoff's original work on the solar spectrum and the interpretation of its lines.

Since that time a great harvest has been gathered in the same field by many reapers. Spectroscopic astronomy has become a distinct and acknowledged branch of the science, possessing a large literature of its own and observatories specially devoted to it. The more recent discovery of the gelatine dry plate has given a further great impetus to this modern side of astronomy, and has opened a pathway into the unknown of which even an enthusiast thirty years ago would scarcely have dared to dream.

In no science, perhaps, does the sober statement of the results which have been achieved appeal so strongly to the imagination, and make so evident the almost boundless powers of the mind of man. By means of its light alone to analyze the chemical nature of a far distant body ; to be able to reason about its present state in relation to the past and future; to measure within an English mile or less per second the otherwise invisible motion which it may have towards or from us; to do more, to make even that which is darkness to our eyes light, and frnm vibrations which our organs of sight are powerless to perceive to evolve a revelation in which we see mirrored some of the stages through which the stars may pass in their slow evolutional progress-surely the record of such achievements, however poor the form of words in which they may be described, is worthy to be regarded as the scientific epic of the present century.

I do not purpose to attempt a survey of the progress of spectroscopic astronomy from its birth at Heidelberg in 1859 , but to point out what we do know at present, as distinguished from what we do not know, of a few only of its more important problems, giving a prominent place, in accordance with the traditions of this chair, to the work of the last year or two.

In the spectroscope itself advances have been made by Lord Rayleigh by his discussion of the theory of the instrument, and by Prof. Rowland in the construction of concave gratings.

Lord Rayleigh has shown that there is not the necessary con. nection, sometimes supposed, between dispersion and resolving power, as besides the prism or grating other details of construction and of adjustment of a spectroscope must be taken into account.

The resolving power of the prismatic spectroscope is proportional to the length of path in the dispersive medium. For the heavy flint glass used in Lord Rayleigh's experiments, the thick. ness necessary to resolve the sodium lines, came out $\mathrm{I}^{\circ} \mathrm{O} 2 \mathrm{~cm}$. If this be taken as a unit, the resolving power of a prism of similar glass will be in the neighbourhood of the sodium lines equal to the number of centimetres of its thickness. In other parts of the spectrum the resolving power will vary inversely as the third power of the wave-length, so that it will be eight times as great in the violet as in the red. The resolving power of a spectroscope is therefore proportional to the total thickness of the dispersive material in use, irrespective of the number, the angles, or the setting of the separate prisms into which, for the sake of convenience, it may be distributed.

The resolving power of a grating depends upon the total number of lines on its surface, and the order of spectrum in use; about 1000 lines being necessary to resolve the sodium lines in the first spectrum.

As it is often of importance in the record of observations to state the efficiency of the spectroscope with which they were made, Prof. Schuster has proposed the use of a unit of purity as well as of resolving power, for the full resolving power of a spectroscrpe is realized in practice only when a sufficiently narrow slit is used. The unit of purity also is to stand for the separation of two lines differing by one-thousandth of their own wavelength; about the separation of the sodium pair at $D$.

A further limitation may come in from the physiological fact that, as Lord Rayleigh has pointed out, the eye, when its full aperture is used, is not a perfect instrument. If we wish to realize the full resolving power of a spectroscope, therefore, the emergent beam must not be larger than about one-third of the opening of the pupil.

Up to the present time the standard of reference for nearly all spectroscopic work continues to be Angström's map of the solar spectrum, and his scale based upon his original determina. tions of absolute wave-length. It is well known, as was pointed out by Thalén in his work on the spectrum of iron, in 1884, that Ångström's figures are slightly too small, in consequence of an error existing in a standard metre used by him. The corrections for this have been introduced into the tables of the wave-lengths of terrestrial spectra collected and revised by a Committee of this Association from 1885 to 1887 . Last year the Committee adedd a table of corrections to Rowland's scale.

The inconvenience cau-ed by a change of standard scale is, for a time at least, considerable ; but there is little doubt that in the near future Rowland's photographic map of the solar spectrum, and his scale based on the determinations of absolute wave-length by Pierce and Bell, or the Potsdam scale based on original determinations by Müller and Kempf, which differs very slightly from it, will come to be exclusively adopted.

The great accuracy of Rowland's photographic map is due chiefly to the introduclion by him of concave gratings, and of a method for their use by which the problem of the determination of relative wave-lengths is simplified to measures of coin. cidences of the lines in different spectra by a micrometer.

The concave grating and its peculiar mounting, in which no lenses or telescope are needed, and in which all the spectra are in focus together, formed a new departure of great importance in the measurement of spectral lines. The valuable method of photographic sensitizers for different parts of the spectrum has enabled Prof. Rowland to include in his map the whole visible solar spectrum, as well as the ultra-violet portion as far as it can get through our atmosphere. Some recent photographs of the solar spectrum, which include A, by Mr. George Higgs, are of great technical beauty.

During the past year the results of three independent researches have appeared, in which the special object of the observers has been to distinguish the lines which are due to our atmosphere from those which are truly solar-the maps of $M$. Thollon, which, owing to his lamented death just before their final completion, have assumed the character of a memorial of him ; maps by Dr. Becker; and sets of photographs of a high and a low sun by Mr. McClean.

At the meeting of this Association in Bath, M. Janssen gave an account of his own researches on the terrestrial lines of the solar spectrum which owe their origin to the oxygen of our atmosphere. He discovered the remarkable fact that, while one class of trands varies as the density of the gas, other diffuse bands vary as the square of the density. These observations are in accordance with the work of Egoroff and of Olszewski, and of Liveing and Dewar on condensed oxygen. In some recent experiments Olszewski, with a layer of liquid oxygen 30 millimetres thick, saw, as well as four other bands, the band coincident with Fraunhofer's A; a remarkahle instance of the persistence of absorption through a great range of temperature. The light which passed through the liquid oxygen had a light blue colour resembling that of the sky.

Of not less interest are the experiments of Knut Angström, which show that the carbonic acid and aqueous vapour of the atmosphere reveal their presence by dark bands in the invisible infra-red region, at the positions of bands of emission of these substances.

It is now some thirty years since the spectroscope gave us for the first time certain knowledge of the nature of the heavenly bodies, and revealed the fundamental fact that terrestrial matter

NO. I I 38 , vOL. 44] 
is not peculiar to the solar system, but is common to all the stars which are visible to us.

In the case of a star such as Capella, which has a spectrum almost identical with that of the sun, we feel justified in concluding that the matter of which it is built up is similar, and that its temperature is also high, and not very different from the solar temperature. The task of analyzing the stars and nebula becomes, however, one of very great difficulty when we have to do with spectra differing from the solar type. We are thrown back upon the laboratory for the information necessary to enable us to interpret the indications of the spectroscope as to the chemical nature, the density and pressure, and the temperature of the celestial masses.

What the spectroscope immediately reveals to us are the waves which were set up in the ether filling all interstellar space, years or hundreds of years ago, by the motions of the molecules of the celestial substances. As a rule, it is only when a body is gaseous and sufficiently hot that the motions within its molecules can produce bright lines and a corresponding absorption. The spectra of the heavenly bodies are, indeed, to a great extent absorption spectra, but we have usually to study them through the corresponding emission spectra of bodies brought into the gaseous form and rendered luminous by means of flames or of electric discharges. In both cases, unfortunately, as has been shown recently by Profs. Liveing and Dewar, Wiillner, E. Wiedemann, and others, there appears to be no certain direct relation between the luminous radiation as shown in the spectroscope and the temperature of the flame, or of the gaseous contents of the vacuum tube-that is, in the usual sense of the term as applied to the mean motion of all the molecules. In buth cases, the vibratory motions within the molecules to which their luminosity is due are almost always much greater than would be produced by encounters of molecules having motions of translation no greater than the average motions which characterize the temperature of the gases as a whole. The temperature of a vacuum tube through which an electric discharge is taking place may be low, as shown by a thermometer, quite apart from the consideration of the extreme smallness of the mass of gas, but the vibrations of the luminous molecules must be violent in whatever way we suppose them to be set up by the discharge; if we take Schuster's view that comparatively few molecules are carrying the discharge, and that it is to the fierce encounters of these alone that the luminosity is due, then if all the molecules had similar motions, the temperature of the gas would be very high.

So in flames where chemical changes are in progress, the vibratory motions of the molecules which are luminous may be, in connection with the energy set free in these changes, very different from those corresponding to the mean temperature of the flame.

Under the ordinary conditions of terrestrial experiments, therefore, the temperature or the mean vis viva of the molecules may have no direct relation to the total radiation, which, on the other hand, is the sum of the radiation due to each luminous molecule.

These phenomena bave recently been discussed by Ebert from the standpoint of the electro-magnetic theory of light.

Very great caution is therefore called for when we attempt to reason by the aid of laboratory experiments to the temperature of the heavenly bodies from their radiation, especially on the reasonable assumption that in them the luminosity is not ordinarily associated with chemical changes or with electrical discharges; but is due to a simple glowing from the ultimate conversion into molecular motion of the gravitational energy of shrinkage.

In a recent paper Stas maintains that electric spectra are to be regarded as distinct from flame spectra, and from researches of his own, that the pairs of lines of the sodium spectrum other than $\mathrm{D}$ are produced only by disruptive electric discharges. As these pairs of lines are found reversed in the solar spectrum, he concludes that the sun's radiation is due mainly to electric discharges. But Wolf and Diacon, and later, Watts, observed the other pairs of lines of the sodium spectrum when the vapour was raised above the ordinary temperature of the Bunsen flame. Recently, Liveing and Dewar saw easily, besides $D$, the citron and green pairs, and sometimes the blue pair and the orange pair, when hydrogen charged with sodium vapour was burning at different pressures in oxygen. In the case of sodium vapour, therefore, and presumably in all other vapours and gases, it is a matter of indifference whether the necessary vibratory motion of the molecules is produced by electric discharges or by flames. The presence of lines in the solar spectrum which we can only produce electrically, is an indication, however, as Stas points out, of the high temperature of the sun.

We must not forget that the light from the heavenly bodies may consist of the combined radiations of different layers of gas at different temperatures, and possibly be further complicated to an unknown extent by the absorption of cooler portions of gas outside.

Not less caution is needed if we endeavour to argue from the broadening of lines and the coming in of a continuous spectrum as to the relative pressure of the gas in the celestial atmospheres. On the one hand, it cannot be gainsaid that in the laboratory the widening of the lines in a Pliicker's tube follows upon increasing the density of the residue of hydrogen in the tube, when the vibrations are more frequently disturbed by fresh encounters, and that a broadening of the sodium lines in a flame at ordinary pressure is produced by an increase of the quantity of sodium in the flame; but it is doubtful if pressure, as distinguished from quantity, does produce an increase of the breadth of the lines. An individual molecule of sodium will be sensibly in the same condition, considering the "relatively enormous number of the molecules of the other gases, whether the flame is scantily or copiously fed with the sodium salt. With a small quantity of sodium vapour the intensity will be feeble except near the maximum of the lines; when, however, the quantity is increased, the comparative transparency on the sides of the maximum will allow the light from the additional molecules met with in the path of the visual ray to strengthen the radiation of the molecules farther back, and so increase the breadth of the lines.

In a gaseous mixture it is found, as a rule, that at the same pressure or temperature, as the encounters with similar molecules become fewer, the spectral lines will be affected as if the body were observed under conditions of reduced quantity or temperature.

In their recent investigation of the spectroscopic behaviour of flames under various pressures up to forty atmospheres, Profs. Liveing and Dewar have come to the conclusion that, though the pro. minent feature of the light emitted by flames at high pressure appears to be a strong continuous spectrum, there is not the slightest indication that this continuous spectrum is produced by the broadening of the lines of the same gases at low pressure. On the contrary, photometric observations of the brightness of the continuous spectrum, as the pressure is varied, show that it is mainly produced by the mutual action of the molecules of a gas. Experiments on the sodium spectrum were carried up to a pressure of forty atmospheres without producing any definite effect on the width of the lines which could be ascribed to the pressure. In a similar way the lines of the spectrum of water showed no signs of expansion up to twelve atmospheres; though more intense than at ordinary pressure, they remained narrow and clearly defined.

It follows, therefore, that a continuous spectrum cannot be considered, when taken alone, as a sure indication of matter in the liquid or the solid state. Not only, as in the experiments already mentioned, such a spectrum may be due to gas when under pressure, but, as Maxwell pointed out, if the thickness of a medium, such as sodium vapour, which radiates and absorbs different kinds of light, be very great, and the temperature high, the light emitted will be of exactly the same composition as that emitted by lamp-black at the same temperature, for the radiations which are feebly emitted will be also feebly absorbed, and can reach the surface from immense depths. Schuster has shown that oxygen, even in a partially exhausted tube, can give a continuous spectrum when excited by a feeble electric discharge.

Compound bodies are usually distinguished by a banded spec. trum; but, on the other hand, such a spectrum does not necessarily show the presence of compounds--that is, of molecules containing different kinds of atoms-but simply of a more com. plex molecule, which may be made up of similar atoms, and be, therefore, an allotropic condition of the same body. In some cases-for example, in the diffuse bands of the absorption spectrum of oxygen-the bands may have an intensity proportional to the square of the density of the gas, and may be due either to the formation of more complex molecules of the gas with increase of pressure, or it may be to the constraint to which the molecules are subject during their encounter with one another.

It may be thought that at least in the coincidences of bright lines we are on the solid ground of certainty, since the length of 
the waves set up in the ether by a molecule, say of hydrogen, is the most fixed and absolutely permanent quantity in nature, and is so of physical necessity, for with any alteration the molecule would cease to be hydrogen.

Such would be the case if the coincidence were certain; but an absolute coincidence can be only a matter of greater or less probability, depending on the resolving power employed, on the number of the lines which correspond, and on their characters. When the coincidences are very numerous, as in the case of iron and the solar spectrum, or the lines are characteristically grouped, as in the case of hydrogen and the solar spectrum, we may regard the coincidence as certain; but the progress of science has been greatly retarded by resting important conclusions upon the apparent coincidence of single lines, in spectroscopes of very small resolving power. In such cases, unless other reasons supporting the coincidence are present, the probability of a real coincidence is al:: ost too small to be of any importance, especially in the case of a heavenly body which may lave a motion of approach or of recession of unknown amount.

But even here we are met by the confusion introduced by multiple spectra, corresponding to different molecular groupings of the same substance; and, further, to the influence of substances in vapour upon each other; for when several gases are present together, the phenomena if radiation and reversal by absorption are by no means the same as if the gases were free from each other's influence, and especially is this the case when they are illuminated by an electric discharge.

I have said as much as time will permit, and I think indeed sufficient, to show that it is only by the laborious and slow process of most cautious observation that the foundations of the science of celestial physics can be surely laid. We are at present in a time of transition, when the earlier, and, in the nature of things, less precise, observations are giving place to work of an order of accuracy much greater than was formerly considered attainable with objects of such small brightness as the stars.

The accuracy of the earlier determinations of the spectra of the terrestrial elements are in most cases insufficient for modern work on the stars as well as on the sun. They fall much below the scale adopted in Rowland's map of the sun, as well as below the degree of accuracy atlained at Potsdam by photography in a part of the spectrum for the brighter stars. Increase of resolving power very frequently breaks up into groups, in the spectra of the sun and stars, the lines which had been regarded as single, and their supposed coincidences with terrestrial lines fall to the ground. For this reason many of the early conclusions, based on observation as good as it was possible to make at the time with the less powerful spectroscopes then in use, may not be found to be maintained under the much greater resolving power of modern instruments.

The spectroscope has failed as yet to interpret for us the re. markable spectrum of the Aurora Borealis. Undoubtedly in this phenomenon portions of our atmosphere are lighted up by electric discharges: we should expect, therefore, to recognize the spectra of the gases known to be present in it. As yet we have not been able to obtain similar spectra from these gases artificially, and especially we do not know the origin of the principal line in the green, which often appears alone, and may have, therefore, an origin independent of that of the other lines. Recently the suggestion has been made that the aurora is a phenomenon proauced by the dust of meteors and falling stars, and that near positions of certain auroral lines or flutings of manganese, lead, barium, thallium, iron, \&c., are sufficient to justify us in regarding meteoric dust in the atmosphere as the origin of the auroral spectrum. Liveing and Dewar have made a conclusive research on this point, by availing themselves of the dust of excessive minuteness thrown off from the surface of electrodes of various metals and meteorites by a disruptive dis. charge, and carried forward into the tube of observation by a more or less rapid current of air or other gas. These experiments prove that metallic dust, however fine, suspended in a gas will not act like gaseous matter in becoming luminous with its characteristic spectrum in an electric discharge similar to that of the aurora. Prof. Schuster has suggested that the principal line may be due to some very light gas which is present in too small a proportion to be detected by chemical analysis or even by the spectroscope in the presence of the other gases near the earth, but which at the height of the auroral discharges is in is sufficiently greater relative proportion to give a spectrum. Lemström, indeed, states that he saw this line in the silent dis- charge of a Holtz machine on a mountain in Lapland. The lines may not have been obtained in our laboratories from the atmospheric gases on account of the difficulty of reproducing in tubes with sufficient nearness the conditions under which the auroral discharges take place.

In the spectra of comets the spectroscope has shown the presence of carbon presumably in combination with hydrogen, and also sometimes with nitrogen; and in the case of comets approaching very near the sun, the lines of sodium, and other lines which have been supposed to belong to iron. Though the researches of Prof. II. A. Newton and of Prof. Schiaparelli leave no doubt of the close connection of comets with corresponding periodic meteor swarms, and therefore of the probable identity of cometary matter with that of meteorites, with which the spectroscopic evidence agrees, it would be perhaps unwise at present to attempt to define too precisely the exact condition of the matter which forms the nucleus of the comet. In any case the part of the light of the comet which is not reflected solar light can scarcely be attributed to a high temperature produced ty the clashing of separate meteoric stones set up within the nucleus by the sun's disturbing force. We must look rather to disruptive electric discharges, produced probably by processes of evaporation due to increased solar heat, which would be amply sufficient to set free portions of the occluded gases into the vacuum of space. May it be that these discharges are assisted, and indeed possibly increased, by the recently discovered action of the ultra-violet part of the sun's light? Lenard and Wolfe have shown that ultra-violet light can produce a discharge from a negatively electrified piece of metal, while Hallwachs and Righi have shown further that ultra-violet light can even charge positively an unelectrified piece of metal. Similar actions on cometary matter, unscreened as it is by an absorptive atmosphere, at least of any noticeable extent, may well be powerful when a comet approaches the sun, and help to explain an electrified condition of the evaporated matter which would possibly bring it under the sun's repulsive action. We shall have to return to this point in speaking of the solar corona.

A very great advance has been made in our knowledge of the constitution of the sun by the recent work at the Johns Hopkins University by means of photography and concave gratings, in comparing the solar spectrum, under great resolving power, directly with the spectra of the terrestrial elements. Prof, Rowland has shown that the lines of thirty-six terrestrial elements at lea-t are certainly present in the solar spectrum, while eight others are doubtful. Fifteen elements, including nitrogen as it shows itself under an electric discharge in a vacuum tube, have not been found in the solar spectrum. Some ten other elements, inclusive of oxygen, have not yet been compared with the sun's spectrum.

Rowland remarks that of the fifteen elements named as not found in the sun, many are so classed because they have few strong lines, or none at all, in the limit of the solar spectrum as compared by him with the arc. Boron has only two strong lines. The lines of bismulh are compound and too diffuse. Therefore even in the case of these fifteen elements there is little evidence that they are really absent from the sun.

It follows that if the whole earth were heated to the tempera. ture of the sun, its spectrum would resemble very closely the solar spectrum.

Rowland has not found any lines common to several elements, and in the case of some accidental coincidences, more accurate investigation reveals some slight difference of wave-Jength or a common impurity. Further, the relative strength of the lines in the solar spectrum is generally, with a few exceptions, the same as that in the electric arc, so that Rowland considers that his experiments show "very little evidence" of the breaking up of the terrestrial elements in the sun.

Stas in a recent paper gives the final results of eleven years of research on the chemical elements in a state of purity, and on the possibility of decomposing them by the physical and chemical forces at our disposal. His experiments on calcium, strontium, lithium, magnesium, silver, sodium, and thallium, show that these substances retain their individuality under all conditions, and are unalterable by any forces that we can bring to bear upon them.

Prof. Rowland looks to the solar lines which are unaccounted for as a means of enabling him to discover such new terrestrial elements as still lurk in rare minerals and earths, by confrontin: their spectra directly with that of the sun. He has already resolved yttrium spectroscopically into three components, and 
actually into two. The comparison of the results of this independent analytical method with the remarkable but different conclusions to which M. Lecoq de Boisbaudran and Mr. Crookes have been led respectively, from spectroscopic observation of these bodies when glowing under molecular bombardment in a vacuum tube, wili be awaited with much interest. It is worthy of remark that, as our knowledge of the spectrum of hydrogen in its complete form came to us from the stars, it is now from the sun that chemistry is probably about to be enriched by the discovery of new elements.

In a discussion in the Bakerian Lecture for 1885 of what we knew up to that time of the sun's corona, I was led to the conclusion that the corona is essentially a phenomenon similar in the cause of its formation to the tails of comets-namely, that it consists for the most part probably of matter going from the sun under the action of a force, possibly electrical, which varies as the surface, and can therefore in the case of highly attenuated matter easily master the force of gravity even near the sun. Though many of the coronal particles may return to the sun, those which form the long rays or streamers do not return; they separate and soon become too diffused to be any longer visible, and may well go to furnish the matter of the zodiacal light, which otherwise has not received a satisfactory explanation. And further, if such a force exist at the sun, the changes of terrestrial magnetism may be due to direct electric action, as the earth moves through lines of inductive force.

These conclusions appear to be in accordance broadly w:th the lines along which thought has been directed by the results of subsequent eclipses. Prof. Schuster takes an essentially similar view, and suggests that there may be a direct electric connection between the sun and the planets. He asks further whether the sun may not act like a magnet in consequence of its revolution about its axis. J'rof. Bigelow has recently treated the coronal forms by the theory of spherical harmonics, on the supposition that we see phenomena similar to those of free electricity, the rays being lines of force, and the coronal matter discharged from the sun, or at least arranged or controlled by these forces. At the extremities of the streams for some reasons the repulsive power may be lost, and gravitation set in, bringing the matter back to the sun. The matter which does leave the sun is persistently transported to the equatorial plane of the corona ; in fact, the zodiacal light may be the accumulation at great distances from the sun along this equator of such like material. Photographs on a larger scale will be desirable for the full development of the conclusions which may follow from this study of the curved forms of the coronal structure. Prof. Schaeberle, however, considers that the coronal phenomena may be satisfactorily accounted for on the supposition that the corona is formed of streams of matter ejected mainly from the spot zones with great initial velocities, but smaller than 382 miles per second. Further that the different types of the corona are due to the effects of perspective on the streams from the earth's place at the time relatively to the plane of the solar equator.

Of the physical and the chemical nature of the coronal matter we know very little. Schuster concludes, from an examination of the eclipses of 1882,1883 , and 1886 , that the continuous spectrum of the corona has the maximum of actinic intensity displaced considerably towards the red when compared with the spectrum of the sun, which shows that it can only be due in small part to solar light scattered by small particles. The lines of calcium and of hydrogen do not appear to form part of the normal spectrum of the corona. The green coronal line has no known representative in terrestrial subitances, nor has Schuster been able to recognize any of our elements in the other lines of the corona.

The spectra of the stars are almost infinitely diversified, yet they can be arranged with some exceptions in a series in which the adjacent spectra, especially in the photographic region, are scarcely distinguishable, passing from the bluish-white stars like Sirius, through stars more or less solar in character, to stars with banded spectra, which divide themselves into two apparently independent groups, according as the stronger edge of the bands is towards the red or the blue. In such an arrangement the sun's place is towards the middle of the series.

At present a difference of opinion exists as to the direction in the series in which evolution is proceeding, whether by further condensation white stars pass into the orange and red stages, or whether these more coloured stars are younger and will become white by increasing age. The latter view was suggested by Johnstone Stoney in 1857 .
About ten years ago Ritter in a series of papers discussed the behaviour of gaseous masses during condensation, and the probable resulting constitution of the heavenly bodies. According to him, a star passes through the orange and red stages twice : first during a comparatively short period of increasing temperature, which culminates in the white stage, and a second time during a more prolonged stage of gradual cooling. $\mathrm{He}$ suggested that the two groups of banded stars may correspond to these different periods: the young stars being those in which the stronger edge of the dark band is towards the blue, the other banded stars, which are relatively less luminous and few in number, being those which are approaching extinction through age.

Recently a similar evolutional order has been suggested, which is based upon the hypothesis that the nebulæ and stars consist of colliding meteoric stones in different stages of condensation.

More recently the view has been put forward that the diversified spectra of the stars do not represent the stages of an evolntional progress, but are due for the most part to differences of original constitution.

The few minutes which can be given to this part of the address are insufficient for a discussion of these different views. I purpose, therefore, to state briefly, and with reserve, as the subject is obscure, some of the considerations from the characters of their spectra which appeared to me to be in favour of the evolutional order in which I arranged the stars from their photographic spectra in 1879 . This order is essentially the same as Vogel had previously proposed in his classification of the stars in 1874 , in which the white stars, which are most numerous, represent the early adult and most persistent stage of stellar life ; the solar condition that of full maturity and of commencing age ; while in the orange and red stars with banded spectra we see the setting in and advance of old age. But this statement must be taken broadly, and not as asserting that all stars, however different in mass and possibly to some small extent in original constitution, exhibit one invariable succession of spectra.

In the spectra of the white stars the dark metallic lines are relatively inconspicuous, and occasionally absent, at the same time that the dark lines of hydrogen are usually strong, and more or less broad, upon a continuous spectrum, which is remarkable for its brilliancy at the blue end. In some of these stars the hydrogen and some other lines are bright, and sometimes variable.

As the greater or less prominence of the hydrogen lines, dark or bright, is characteristic of the white stars as a class, and diminishes gradually $w$ ith the incoming and increase in strength of the other lines, we are probably justified in regarding it as due to some conditions which occur naturally during the progress of stellar life, and not to a peculiarity of original constitution.

To produce a strong absorption-spectrum a substance must be at the particular temperature at which it is notably absorptive ; and, further, this temperature must be sufficiently below that of the region behind from which the light comes for the gas to appear, so far as its special rays are concerned, as darkness upon it. Considering the high temperature to which hydrogen must be raised before it can show its characteristic emission and absorption, we shall probably be right in attributing the relative feebleness or absence of the other lines, not to the paucity of the metallic vapours, but rather to their being so hot relatively to the substances behind them as to show feebly, if at all, by reversion. Such a state of things would more probably be found, it seems to me, in conditions anterior to the solar stage. A considerable cooling of the sun would probably give rise to banded spectra due to compounds, or to more complex molecules, which might form near the condensing points of the vapours.

The sun and stars are generally regarded as consisting of glowing vapours surrounded by a photosphere where condensation is taking place, the temperature of the photospheric layer from which the greater part of the radiation comes being constantly renewed from the hotter matter within.

At the surface the convection currents would be strong, producing a considerable commotion, by which the different gases would be mixed and not allowed to retain the inequality of proporiions at different levels due to their vapour densities.

Now the conditions of the radiating photosphere and those of the gases above it, on which the character of the spectrum of a star depends, will be determined, not alone by temperature, but also by the force of gravity in these regions; this force will be fixed by the star's mass and its stage of condensation, and will become greater as the star continues to condense. 
In the case of the sun the force of gravity has already become so great at the surface that the decrease of the density of the g zies must be extremely rapid, passing in the space of a few miles from atmospheric pressure to a density infinitesimally small ; consequently the temperature-gradient at the surface, if determined solely by expansion, must be extremely rapid. The gases here, however, are exposed to the fierce radiation of the sun, and unless wholly transparent would take up heat, especially if any solid or liquid particles were present from condensation or convection currents.

From these causes, within a very small extent of space at the surface of the sun, all bodies with which we are acquainted should fall to a condition in which the extremely tenuous gas could no longer give a visible spectrum. The insignificance of the angle subtended by this space as seen from the earth should cause the boundary of the solar atmosphere to appear defined. If the boundary which we see be that of the sun proper, the matter above it will have to be regarded as in an essentially dy. namical condition - an assemblage, so to speak, of gaseous projectiles for the most part falling back upon the sun after a greater or less range of flight. But in any case it is within a space of relatively small extent in the sun, and probably in the other solar stars, that the reversion which is manifested by dark lines is to be regarded as taking place.

Passing backward in the star's life, we should find a gradual weakening of gravity at the surface, a reduction of the temperature-gradient so far as it was determined by expansion, and con. vection currents of less violence producing less interference with che proportional quantities of gases due to their vapour densities, while the effects of eruptions would be more extensive.

At last we might come to a state of things in which, if the star were hot enough, only hydrogen might be sufficiently cool relatively to the radiation behind to produce a strong absorption. The lower vapours would be protected, and might continue to be relatively too hot for their lines to appear very dark upon the continuous spectrum; besides, their lines might be possibly to some extent effaced by the coning in under such conditions in the vapours themselves of a continuous spectrum.

In such a star the light radiated towards the upper part of the atmosphere may have come from portions lower down of the atmosphere itself, or at least from parts not greatly hotter. There may be no such great difference of temperature of the low and less low portions of the star's atmosphere as to make the darkening effect of absorption of the protected metallic vapours to prevail over the illuminating effect of their emission.

It is only by a vibratory motion corresponding to a very high temperature that the bright lines of the first spectrum of hydrogen can be brought out, and by the equivalence of absorbing and emitting power that the corresponding spectrum of absorption should be produced; yet for a strong absorption to show itself, the hydrogen must be cool relatively to the source of radiation behind it, whether this be condensed particles or gas. Such conditions, it seems to me, should occur in the earlier rather than in the more advanced stages of condensation.

The subject is obscure, and we may go wrong in our mode of conceiving of the probable progress of events, but there can be no doubt that in one remarkable instance the white-star spectrum is associated with an early stage of condensation.

Sirius is one of the most conspicuous examples of one type of this class of stars. Photometric obcervations combined with its ascertained parallax show that this star emits from forty to sixty times the light of our sun, even to the eye, which is insensible to ultra-violet light, in which Sirius is very rich, while we learn from the motion of its companion that its mass is not much more than double that of our sun. It follows that, unless we attribute to this star an improbably great emissive power, it must be of immense size, and in a much more diffuse and therefore an earlier condition than our sun; though probably at a later stage than those whitestars in which the hydrogen lines are bright.

$A$ direct determination of the relative temperature of the photospheres of the stars might possibly be obtained in some cases from the relative position of maximum radiation of their continuous spectra. Langley has shown that through the whole range of temperature on which we can experiment, and presumably at temperalures beyond, the maximum of radiation-power in solid bodies gradually shifts upwards in the spectrum from the infra-red through the red and orange, and that in the sun it has reached the blue.

The defined character, as a rule, of the stellar lines of absorp. tion suggests that the vapours producing them do not at the ;ome time exert any strong power of general absorption. Consequently, we should probably not go far wrong, when the photosphere consists of liquid or solid particles, if we could compare select parts of the continuous spectrim between the stronger lines, or where they are fewest. It is obvious that, if extended portions of different stellar spectra were compared, their true relation wo:ld be obscured by the line-absorption.

The increase of temperature, as shown by the rise in the pectrum of the maximum of radiation, may not always be accompanied by a corresponding greater brightness of a star as estimated by the eye, which is an extremely imperfect photometric instrument. Not only is the eye blind to large region of radiation, but even for the small range of light that we can see the visual effect varies enormously with its colour. According to Prof. Langley, the same amount of energy which just enables us to perceive light in the crimson at $\mathrm{A}$ would in the green produce a visual effect 100,000 times greater. In the violet the proportional effect would be 1600 , in the blue 62,000 , in the yellow 28,000 , in the orange 14,000 , and in the red 1200 . Captain Abney's recent experiments make the sensitiveness of the eye for the green near $F$ to be 750 times greater than for the red about C. It is for this reason, at least in part, that I suggested in 1864 , and have since shown by direct observation, that the spectrum of the nebula in Andromeda, and presumably of similar nebulæe, is, in appearance, only wanting in the red.

The stage at which the maximum radiation is in the green, corresponding to the eye's greatest sensitiveness, would ba that in which it could be most favourably measured by eje-photometry. As the maximum rose into the violet and beyond, the star would increase in visual brightness, but not in proportion to the increase of energy radiated by it.

The brightness of a star would be affected by the nature of the substance by which the light was chiefly emitted. In the laboratory, solid carbon exhibits the highest emissive power. A stellar stage in which radiation comes, to a large extent, from a photosphere of the solid particles of this substance, would be favourable for great brilliancy. Though the stars are built up of matter essentially similar to that of the sun, it does not follow that the proportion of the different elements is everywhere the same. It may be that the substances condensed in the photospheres of different stars may differ in their emissive powers, but probably not to a great extent.

All the heavenly bodies are seen by us through the tinted medium of our atmosphere. According to Langley, the solar stage of stars is not really yellow, but, even as gauged by our imperfect eyes, would appear bluish-white if we could free ourselves from the deceptive influences of our surroundings.

From these considerations it follows that we can scarcely infer the evolutional stages of the stars from a simple comparison of their eye-magnitudes. We should expect the white stars to be, as a class, less dense than the stars in the solar stage. As great mass might bring in the solar type of spectrum at a rela. tively earlier time, some of the brightest of these stars may b3 very massive, and brighter than the sun-for example, the brilliant star Arcturus. For these reasons the solar stars should not only be dense than the white stars, but perhaps, as a class, surpass them in mass and eye-brightness.

It has been shown by Lane that, so long as a condensing gaseous mass remains subject to the laws of a purely gaseous body, its temperature will continue to rise.

The greater or less breadth of the lines of absorption of hydrogen in the white stars may be due to variations of the depth of the hydrogen in the line of sight, arising from the causes which have been discussed. At the sides of the lines the absorption and emission are feebler than in the middle, and would come out more strongly with a greater thickness of gas.

The diversities among the white stars are nearly as numerous as the individuals of the class. Time does not permit me to do more than to record that, in addition to the three sub-classes into which they have been divided by Vogel, Scheiner has recently investigated minor differences as suggested by the character of the third line of hydrogen near $G$. He has pointed out, too, that so far as his observations go the white stars in the constellation of Orion stand alone, with the exception of Algol, in possessing a dark line in the blue which has apparently the same position as a bright line in the great nebula of the same constellation; and Pickering finds in his photographs of the spectra of these stars dark lines corresponding to the principal lines of the bright-line stars, and the planetary nebula with the

$$
\text { NO. I I } 38 \text {, VOL. } 44 \text { ] }
$$


exception of the chief nebular line. The association of white stars with nebular matter in Orion, in the Pleiades, in the region of the Milky Way, and in other parts of the heavens, may be regarded as falling in with the view that I have taken.

In the stars possibly further removed from the white class than our sun, belonging to the first division of Vogel's third class, which are distinguished by absorption bands with their stronger edge towards the blue, the hydrogen lines are narrower than in the solar spectrum. In these stars the density-gradient is probably still more rapid, the depth of hydrogen may be less, and possibly the hydrogen molecules may be affected by a larger number of encounters with dissimilar molecules. In some red stars with dark hydrocarbon bands, the hydrogen lines have not been certainly observed; if they are really absent, it may be because the temperature has fallen below the point at which hydrogen can exert its characteristic absorption ; besides, some hydrogen will have united with the carbon. The coming in of the hydrocarbon bands may indicate a later evolutional stage, but the temperature may still be high, as acetylene can exist in the electric arc.

A number of small stars more or less similar to those which are known by the names of their discoverers, Wolf and Rayet, have been found by Pickering in his photographs. These are remarkable for several brilliant groups of bright lines, including frequently the hydrogen lines and the line $\mathrm{D}_{3}$, upon a continuous spectrum strong in blue and violet rays, in which are also dark lines of absorption. As some of the bright groups appear in his photographs to agree in position with corresponding bright lines in the planetary nebula, Pickering suggests that these stars should be placed in one class with them, but the brightest nebular line is absent from these stars. The simplest conception of their nature would be that each star is surrounded by a nebula, the bright groups being due to the gaseous matter outside the star. Mr. Roberts, however, has not been able to bring out any indication of nebulosity by prolonged exposure. The remarkable star $\eta$ Argûs may belong to this class of the heavenly bodies.

In the nebulæ, the elder Herschel saw portions of the fiery mist or "shining fluid" out of which the heavens and the earth had been slowly fashioned. For a time this view of the nebulæ gave place to that which regarded them as external galaxies, cosmical "sand-heaps," too remote to be resolved into separate stars; though indeed, in $185^{8}, \mathrm{Mr}$. Herbert Spencer showed that the observations of nebulæ up to that time were really in favour of an evolutional progress.

In 1864 , I brought the spectroscope to bear upon them; the bright lines which flashed upon the eye showed the source of the light to be glowing gas, and so restored these bodies to what is probably their true place, as an early stage of sidereal life.

At that early time our knowledge of stellar spectra was small. For this reason partly, and probably also under the undue influence of theological opinions then widely prevalent, I unwisely wrote in my original paper in I864, "that in these objects we no longer have to do with a special modification of our own type of sun, but find ourselves in presence of objects possessing a distinct and peculiar plan of structure." Two years later, however, in a lecture before this Association, I took a truer position. "Our views of the universe," I said, "are undergoing important changes; let us wait for more facts, with minds unfettered by any dogmatic theory, and therefore free to receive the teaching, whatever it may be, of new observations."

Let us turn aside for a moment from the nebulæ in the sky to the conclusions to which philosophers had been irresistibly led by a consideration of the features of the solar system. We have before us in the sun and planets obviously not a haphazard aggregation of bodies, but a system resting upon a multitude of relations pointing to a common physical cause. From these considerations Kant and Laplace formulated the nebular hypothesis, resting it on gravitation alone, for at that time the science of the conservation of energy was practically unknown. These philosophers showed how, on the supposition that the space now occupied by the solar system was once filled by a vaporous mass, the formation of the sun and planets could be reasonably accounted for.

By a totally different method of reasoning, modern science traces the solar system backward step by step to a similar state of things at the beginning. According to Helmholtz, the sun's heat is maintained by the contraction of his mass, at the rate of about 220 feet a year. Whether at the present time the sun is getting hotter or colder we do not certainly know. We can reason back to the time when the sun was sufficiently expanded to fill the whole space occupied by the solar system, and was reduced to a great glowing nebula. Though man's life, the life of the race perhaps, is too short to give us direct evidence of any distinct stages of so august a process, still the probability is great that the nebular hypothesis, especially in the more precise form given to it by Roche, does represent broadly, notwithstanding some difficulties, the succession of events through which the sun and planets have passed.

The nebular hypothesis of Laplace requires a rotating mass of fluid which at successive epochs became unstable from excess of motion, and left behind rin $x$, or more probably perhaps lumps, of matter from the equatorial regions.

The difficulties to which I have referred have suggested to some thinkers a different view of things, according to which it is not necessary to suppose that one part of the system gravita. tionally support; another. The whole $m$ iy consist of a congeries of discrete bodies even if these bodies be the ultimate molecules of matter. The planets may have been formed by the gradual accretion of such discrete bodies. On the view that the material of the condensing solar system consisted of separate particles or masses, we have no longer the fluid pressure which is an essential part of Laplace's theory. Faye, in his theory of evolution from meteorites, has to throw over this fundamental idea of the nebular hypothesis, and he formulates instead a different succession of events, in which the outer planets were formed last; a theory which has difficulties of its own.

Prof. George Darwin has recently shown, from an investigation of the mechanical conditions of a swarm of meteorites, that on certain assumptions a meteoric swarm might behave as a coarse gas, and in this way bring back the fluid pressure exercised by one part of the system on the other, which is require.I by Laplace's theory. One chief assumption consists in supposing that such inelastic bodies as meteoric stones might attain the effective elasticity of a high order which is necessary to the theory through the sudden volatilization of a part of their mass at an encounter, by which what is virtually a violent explosive is introduced between the two colliding stones. Prof. Darwin is careful to point out that it must necessarily be obscure as to how a small mass of solid matter can take up a very large amount of energy in a small fraction of a second.

Any direct indications from the heavens themselves, however slight, are of so great value, that I should perhaps in this connection call attention to a recent remarkable photograph, by $\mathrm{Mr}$. Roberts, of the great nebula in Andromeda. On this plate we seem to have presented to us some stage of cosmical evolution on a gigantic scale. The photograph shows a sort of whirlpool disturbance of the luminous matter which is distributed in a plane inclined to the line of sight, in which a series of rings of bright matter separated by dark spaces, greatly foreshortened by perspective, surround a large undefined central mass. We are ignorant of the parallax of this nebula, but there can be little doubt that we are looking upon a system very remote, and therefore of a magnitude great beyond our power of adequate comprehension. The matter of this nebula, in whatever state it may be, appears to be distributed, as in so many other nebula, in rings or spiral streams, and to suggest a stage in a succession of evolutional events not inconsistent with that which the nebular hypothesis requires. To liken this object more directly to any particular stage in the formation of the solar system would be "to compare things great with small," and might be indeed to introduce a false analogy; but, on the other hand, we should err through an excess of caution if we did not accept the remarkable features brought to light by this photograph as a presumptive indication of a progress of events in cosmical history following broadly upon the lines of Laplace's theory.

The old view of the original matter of the nebulx, that it consisted of a "fiery mist,"

$$
\begin{aligned}
& \text { "a tumultuous cloud } \\
& \text { Instinct with fire and nitre," }
\end{aligned}
$$

fell at once with the rise of the science of thermodynamics. In 1854 , Helmholtz showed that the supposition of an original fiery condition of the nebulous stuff was unnecessary, since in the mutual gravitation of widely separated matter we have a store of potential energy sufficient to generate the high temperature of the sun and stars. We can scarcely go wrong in attributing the light of the nebulæ to the conversion of the gravitational enersy of shrinkage into molecular motion.

The idea that the light of comets and of nebulæ may be due

NO. I I 38 , VOL. 44] 
to a succession of ignited flashes of gas from the encounters of meteoric stones was suggested by Prof. Tait, and was brought to the notice of this Asiociation in 1871 by Sir William Thomson in his Presidential Address.

The spectrum of the bright-line nebulæ is certainly not such a spectrum as we should expect from the flashing by collisions of meteorites similar to those which have been analyzed in our laboratories. The strongest lines of the substances which in the case of such meteorites would first show themselves, iron, sodium, magnesium, nickel, \&c., are not those which distinguish the nebular spectrum. On the contrary, this spectrum is chiefly remarkable for a few brilliant lines, very narrow and defined, upon a background of a faint continuous spectrum, which contains numerous bright lines, and probably some lines of absorption.

The two most conspicuous lines have not been interpreted; for though the second line falls near, it is not coincident with a strong double line of iron. It is hardly necessary to say that though tive near position of the brightest line to the bright double line of nitrogen, as seen in a small spectroscope in 1864 , naturally suggested at that early time the possibility of the presence of this element in the nehule, I have been careful to point out, to prevent misapprehension, that in more recent years the nitrogen line and subsequently a lead line have been employed by me solely as fiducial points of reference in the spectrum.

The third line we know to be the second line of the first spec1rum of hydrogen. Mr. Keeler has seen the first liydrogen line in the red, and photographs show that this hydrogen spectrum is probably present in its complete form, or nearly so, as we first learnt to know it in the absorption spectrum of the white stars.

We are not surprised to find associated with it the line $D_{3}$, near the position of the absent sodium lines, probably due to the atom of some unknown gas, which in the sun can only show itself in the outbursts of highest temperature, and for this reason does not reveal itself by absorption in the solar spectrum.

It is not unreasonable tc assume that the two brightest lines, which are of the same order, are produced by substances of a similar nature, in which a vibratory motion corresponding to a very high temperature is also necessary. These substances, as well as that represented by the line $\mathrm{D}_{3}$, may be possibly some of the unknown elements which are wanting in our terrestrial chemistry between hydrogen and lithium, unless indeed $D_{3}$ be on the lighter side of hydrogen.

In the laboratory we must have recourse to the electric discharge to bring out the spectrum of hydrogen; but in a vacuum. tube, though the radiation may be great, from the relative few ness of the luminous atoms or molecules or from some other cause, the temperature of the gas as a whole may be low.

On account of the large extent of the nebulæ, a comparatively small number of luminous molecules or atoms would probably be sufficient to make the nebulxe as bright as they appear to us. On such an assumption the average temperature may re low, but the individual particles, which by their encounters are luminous, must have motions corresponding to a very high temperature, and in this sense be extremely hot.

In such diffuse masses, from the great mean length of free path, the encounters would $b_{r}$ "are but correspondingly violent, and tend to bring about viurations of comparatively shor period, as appears to be the case if we may judge by the great relative brightress of the more refrangible lines of the nebular spectrum.

Such a view may perhaps reconcile the high temperature which the nebular spectrum undoubtedly suggests with the much lower mean temperature of the gaseous mass, which we should expect at so early a stage of condensation, unless we assume a very enormous mass; or that the matter coming together had preriously considerable motion, or considerable molecular agitation.

The inquisitiveness of the human mind does not allow us to remain content with the interpretation of the present state of the cosmical masses, but suggests the question-

$$
\begin{aligned}
& \text { "What see'st thou else } \\
& \text { In the dark backward and abysm of time?" }
\end{aligned}
$$

What was the original state of things? how has it come about that by the side of ageing worlds we have nebula in a relatively younger stage? Have any of them received their birth from dark suns, which have collidard into new life, and so belong to a second or later generation of the heavenly bodies?

During the short historic period, indeed, there is no record of such an event; still it would seem to be only through the collision of dark suns, of which the number must be increasing, that a temporary rejuvenescence of the heavens is possible, and by such ebbings and flowings of stellar life that the inevitable end to which evolution in its apparently uncompensated progress is carrying us can, even for a little, be delayed.

We cannot refuse to admit as possible such an origin for nebulæ.

In considering, however, the formation of the existing nebula we must bear in mind that, in the part of the heavens within our ken, the stars still in the early and middle stages of evolution exceed greatly in number those which appear to be in an advanced condition of condensation. Indeed, we find some stars which may be regarded as not far advanced beyond the nebular condition.

It may be that the cosmical bodies which are still nebulous owe their later development to some conditions of the part of space where they occur, such as, conceivably, a greater original homogeneity, in consequence of which condensation began lass early. In other parts of space condensation may have been still further delayed, or even have not yet begun. It is worthy of remark that these nebulæ group themselves about the Milky Way, where we find a preponderance of the white-star type of stars, and almost exclusively the bright-line stars which Pickering associates with the planetary nebulæ. Further, Dr. Gill conclurles, from the rapidity with which they impress themselves upon the plate, that the fainter stars of the Milky Way also, to a large extent, belong to this early type of stars. At the same time other types of stars occur also over this region, and the red hydrocarbon stars are found in certain parts; but possibly these stars may be before or behind the Milky Way, and not physically connected with it.

If light matter be suggested by the spectrum of these nebulæ, it may be asked further, as a pure speculation, whether in them we are witnessing possibly a later condensation of the light matter which had been left behind, at least in a relatively greater proportion, after the first growth of worlds into which the heavier matter condensed, though not without some entanglement of the lighter substances. The wide extent and great diffuseness of this bright-line nebulosity over a large part of the constellation of Orion may be regarded perhaps as pointing in this direction. The diffuse nebulous matter streaming round the Pleiades may possibly be another instance, though the character of its spectrum has not yet been ascertained.

In the planetary nebulæ, as a rule, there is a sensible increase of the faint continuous spectrum, as well as a slight thickening of the bright lines towards the centre of the nebula, appearances which are in favour of the view that these bodies are condensing gaseous masses.

Prof. G. Darwin, in his investigation of the equilibrium of a rotating mass of fluid, found, in accordance with the independent researches of Poincaré, that when a portion of the central body becomes detached through increasing angular velocity, the portion should bear a far larger ratio to the remainder than is observed in the planets and satellites of the solar system, even taking into account heterogeneity from the condensation of the parent mass.

Now this state of things, in which the masses though not equal are of the same order, does seem to prevail in many nebulæ, and to have given birth to a large class of binary stars. Mr. See has recentiy investigated the evolution of bodies of this class, and points out their radical differences from the solar system in the relatively large mass-ratios of the component bodies, as well as in the high eccentricities of their orbits brought about by tidal friction, which would play a more im. portant part in the evolution of such systems.

Considering the large number of these bodies, he suggests that the solar system should perhaps no longer be regarded as representing celestial evolution in its normal form-

$$
\text { "A goodly Paterne to whose perfect mould }
$$$$
\text { He fashioned them }
$$

but rather as modified by conditions which are exceptional.

It may well be that in the very early stages condensing masses are subject to very different conditions, and that condensation may not always begin at one or two centres, but sometimes set in at a large number of points, and proceed in the different cases along very different lines of evolution.

Besides its more direct use in the chemical analysis of the heavenly bodies, the spectroscope has given to us a great and 
unexpected power of advance along the lines of the older astronomy. In the future, a higher value may, indeed, be placed upon this indirect use of the spectroscope than upon its chemical revelations.

By no direct astronomical methods could motions of approach or of recession of the stars be even detected, much less could they be measured. A body coming directly towards us or going directly from us appears to stand still. In the case of the stars we can receive no assistance from change of size or of brightness. The stars show no true disks in our instruments, and the nearest of them is so far off that if it were approaching us at the rate of a hundred miles in a second of time, a whole century of such rapid approach would not do more than increase its brightness by the one-fortieth part.

Still it was only too clear that, so long as we were unable to ascertain directly those components of the stars' motions which lie in the lire of sight, the speed and direction of the solar motion in space, and many of the great problems of the consti tution of the heavens, must remain more or less imperfectly known. Now the spectroscope has placed in our hands this power, which, though so essential, appeared almost in the nature of things to lie for ever beyond our grasp; it enables us to measure directly, and under favourable circumstances to within a mile per second, or even less, the speed of approach or of recession of a heavenly body. This method of observation has the great advantage for the astronomer of being independent of the distance of the moving body, and is therefore as applicable and as certain in the case of a bocty on the extreme confines of the visible universe, so long as it is bright enough, as in the case of a neighbouring planet.

Doppler had suggested as far back as $\mathrm{I} 84 \mathrm{I}$ that the same principle, on which he had shown that a sound should become sharper or flatter if there were an approach or a recession between the ear and the source of the sound, would apply equally to light; and he went on to say that the difference of colour of some of the binary stars might be produced in this way by their motions. Doppler was right in that the principle is true in the case of light, but he was wrong in the particular conclusion which he drew from it. Even if we suppose a star to b: moving with a sufficiently enormous velocity to alter sensibly its colour to the eye, no such change would actually be seen, for the reason that the store of invisible light beyond both I mits of the visible spectrum, the blue and the red, would bc drawn upon, and light-waves invi-ible to us would be exalted or degraded so as to take the place of those raised or lowered in the visible region, and the colour of the star would remain unchanged. About eight years later Fizeau pointed out the importance of considering the individual wave-lengths of which white light is composed. As soon, however, as we had learned to recognize the lines of known substances in the spectra of the heavenly bodies, Doppler's principle became applicable as the basis of a new and most fruitful method of investigation. The measurement of the small shift of the celestial lines from their true positions, as shown by the same lines in the spectrum of a terrestrial substance, gives to us the means of ascertaining directly in miles per second the speed of approach or of recession of the heavenly body from which the light has come.

An account of the first application of this method of research to the stars, which was made in my observatory in 1868 , was given by Sir Gabriel Stokes from this chair at the meeting at Exeter in I869. The stellar motions determined by me were shortly after confirmed by Prof. Vogel in the case of Sirius, and in the case of other stars by Mr. Christie, now AstronomerRoyal, at Greenwich; but, necessarily, in consequence of the inadequacy of the instruments then in use for so delicate an inquiry, the amounts of these motions were but approximate.

The method was shortly afterwards taken up systematically at Greenwich and at the Rugby Observatory. It is to be greatly regretted that, for some reasons, the results have not been sufficiently accordant and accurate for a research of such exceptional delicacy. On this account probably, as well as that the spectroscope at that early time had scarcely become a familiar instrument in the observatory, astronomers were slow in availing themselves of this new and remarkable power of investigation. That this comparative neglect of so truly wonderful a method of ascertaining what was otherwise outside our powers of observation has greatly retarded the progress of astronomy during the last fifteen years, is but too clearly shown by the brilliant results which within the last couple of years have followed fast upon the recent masterly application of this method by photography at Potsdam, and by eye with the needful accuracy at the Lick Observatory. At last this use of the spectroscope has taken its true place as one of the most potent methods of astronomical research. It gives us the motions of approach and of recession, not in angular measures, which depend for their translation into actual velocities upon separate determinations of paraliactic displacements, but at once in terrestrial units of distance.

This method of work will doubtless be very prominent in the astronomy of the near future, and to it probably we shall have to look for the more important discoveries in sidereal astronomy which will be made during the coming century.

In his recent application of photography to this method of determining celestial motions, Prof. Vogel, assisted by Dr. Scheiner, considering the importance of obtaining the spectrum of as many stars as possible on an extended scale without an exposure inconveniently long, wisely determined to limit the part of the spectrum on the plate to the region for which the ordinary silver-bromide gelatine plates are most sensitivenamely, to a small distance on each side of $\mathrm{G}$-and to employ as the line of comparison the hydrogen line near $G$, and recently also certain lines of iron. The most minute and complete mechanical arrangements were provided for the purpose of securing the absolute rigidity of the comparison spectrum relatively to that of the star, and for permitting temperature adjustments and other necessary ones to be made.

The perfection of these spectra is shown by the large number of lines, no fewer than 250 in the case of Capella, within the small region of the spectrum on the plate. Already the motions of about fifty stars have been measured with an accuracy, in the case of the larger number of them, of about an English mile per second.

At the Lick Observatory it has been shown that observations can be made directly by eye with an accuracy equally great. Mr. Keeler's brilliant success has followed in great measure from the use of the third and fourth spectra of a grating 14,438 lines to the inch. The marvellous accuracy attainable in his hands on a suitable star is shown by observations on three nights of the star Arcturus, the largest divergence of his measures being not greater than six tenths of a mile per second, while the mean of the three nights' work agreed with the mean of five photographic determinations of the same star at Potsdam to within one-tenth of an English mile. These are determinations of the motions of a sun so stupendously remote that even the method of parallax practically fails to fathom the depth of intervening space, and by means of light-waves which have been according to Elkin's nominal parallax, nearly 200 years upon their journey.

Mr. Keeler, with his magnificent means, has accomplished a task which I attempted in vain in 1874 , with the comparatively poor appliances at my disposal, of measuring the motions in the line of sight of some of the planetary nebulx. As the stars have considerable motions in space, it was to be expected that nebula should possess similar motions, for the stellar motions must have belonged to the nebulæ out of which they have been evolved. My instrumental means, limiting my power of detection to motions greater than twenty-five miles per second, were in. sufficient. Mr. Keeler has found in the examination of ten nebulæ motions varying from two miles to twenty-seven miles, with one exceptional motion of nearly forty miles.

For the nebula of Orion, Mr. Keeler finds a motion of recession of about ten miles a second. Now this motion agrees closely with what it should appear to have from the drift of the solar system itself, so far as it has been possible at present to ascertain the probable velocity of the sun in space. This grand nebula, of vast extent and of extreme tenuity, is probably more nearly at rest relatively to the stars of our system than any other celestial object we know ; still it would seem more likely that even here we have some motion, small though it may be, than that the motions of the matter of which it is formed were so absolutely balanced as to leave this nebula in the unique position of atsolute immobility in the midst of whirling and drifting suns and systems of suns.

The spectroscopic method of determining celestial motions $i$, the line of sight has recently become fruitful in a new but not altogether unforeseen direction, for it has, so to speak, given us a separating power far beyond that of any telescope the glassmaker and the optician could construct, and so enabled us to penetrate into mysteries hidden in stars apparently single, and altogether unsuspected of being binary systems. The spectro scope has not simply added to the list of the known binary stars, but has given to us for the first time a knowledge of a new clas 
of stellar systems, in which the components are in some cases of nearly equal magnitude, and in close proximity, and are revolving with velocities greatly exceeding the planetary velocities of our system.

The $\mathrm{K}$ line in the photographs of Mizar, taken at the Harvard College Observatory, was found to be double at intervals of fifty-two days. The spectrum was therefore not due to a single source of light, but to the combined effect of two stars moving periodically in opposite directions in the line of sight. It is obvious that if two stars revolve round their common centre of gravity in a plane not perpendicular to the line of sight, all the lines in a spectrum common to the two stars will appear alternately single or double.

In the case of Mizar and the other stars to be mentioned, the spectroscopic observations are not as yet extended enough to furnish more than an approximate determination of the elements of their orbits.

Mizar especially, on account of its relatively long periodabout 105 days-needs further observations. The two stars are moving each with a velocity of about fifty miles a second, probably in elliptical orbits, and are about 143 millions of miles apart. The stars, of about equal brightness, bave together a mass about forty times as great as that of our sun.

A similar doubling of the lines showed itself in the Harvard photographs of $\beta$ Aurigæ at the remarkably close interval of almost exactly two days, indicating a period of revolution of about four days. According to Vogel's later observations, each star has a velocity of nearly seventy miles a second, the distance between the stars being little more than seven and a half millions of miles, and the mass of the system $4^{*} 7$ times that of the sun. The system is approaching us at the speed of about sixteen miles a second.

The telescope could never have revealed to us double stars of 1his order. In the case of $\beta$ Auriga, combining Vogel's distance with Pritchard's recent determination of the star's parallax, the greatest angular separation of the stars as seen from the earth would be $1 / 200$ part of a second of arc, and therefore very far too small for the highest powers of the largest telescopes. If we take the relation of aperture to scparating power usually accepted, an object-glass of about 80 feet in diameter would be needed to resolve this binary star. The spectroscope, which takes no note of distance, magnifies, so to speak, this minute angular separation 4000 times; in other words, the doubling of the lines, which is the phenomenon that we have to observe, amounts to the easily measurable quantity of twenty seconds of arc.

There were known, indeed, variable stars of short period, which it had been suggested might be explained on the hypothesis of a dark body revolving about a bright sun in a few days, but this theory was met by the objection that no such systems of closely revolving suns were known to exist.

The Harvard photographs of which we have been speaking, were taken with a slitless form of spectroscope, the prisms being placed, as originally by Fraunhofer, before the object-glass of the telescope. This method, though it possesses some advantages, has the serious drawback of not permitting a direct comparison of the star's spectrum with terrestrial spectra. It is obviously unsuited to a variable star like Algol, where one star only is bright, for in such a case there would be no doubling of the lines, but only a small shift to and fro of the lines of the lisight star as it moved in its orbit alternately towards and from our system, which would need for its detection the fiducial positions of terrestrial lines compared directly with them.

For such observations the Potsdam spectrograph was well adapted. Prof. Vogel found that the bright star of Algol did pulsate backwarcls and forwards in the visual direction in a period corres jor ding to the known variation of its light. The explanation wlichl lad bcen suggested for the star's variability, that it was partially eclipsed at regular intesvals of 68.8 hour by a dark companion large enough to cut off nearly five-sixths of its light, was therefore the true one. The dark companion, no longer able to hide itself by its obscureness, was brought out into the light of direct observation by means of its gravitational effects.

Seventeen hours before minimum, Algol is receding at the rate of about $24 \frac{1}{2}$ miles a second, while seventeen hours after minimum it is found 10 be approaching with a speed of about $28 \frac{1}{2}$ miles. From these data, together with those of the variation of its light, Vogel found, on the assumption that both stars lave the same density, that the cumpanion, nearly as large as the sun, but with about one-fourth his mass, revolves with a velocity of about fifty-five miles a second. The bright star, of about twice the size and mass, moves about the common centre of gravity with the speed of about twenty-six miles a second. The system of the two stars, which are about $3 \frac{1}{4}$ millions of miles apart, considered as a whole, is approaching us with a velocity of 2.4 miles a second. The great difference in luminosity of the two stars, not less than fifty limes, suggests rather that they are in different stages of condensation, and dissimilar in density.

It is obvious that if the orbit of a star with an obscure companion is inclined to the line of sight, the companion will pass above or below the bright star, and produce no variation of its light. Such systems may be numerous in the heavens. In Vogel's photographs, Spica, which is not variable, by a small shifting of its lines reveals a backward and forward periodical pulsation due to orbital motion. As the pair whirl round their common centre of gravity, the bright star is sometimes advancing, at others receding. They revolve in about four days, each star moving with a velocity of about fifty-six miles a second in an orbit probably nearly circular, and possess a combined mass of rather more than two and a half times that of the sun. Taking the most probable value for the star's parallax, the greatest angular separation of the stars would be far too small to be detected with the most powerful telescopes.

If in a close double star the fainter companion is of the whitestar type, while the bright star is solar in character, the composite spectrum would be solar with the hydrogen lines unusually strong. Such a spectrum would in itself afford some probability of a double origin, and suggest the existence of a companion star.

In the case of a true binary star the orbital motions of the pair would reveal themselves in a small periodical swaying of the hydrogen lines relatively to the solar ones.

Prof. Pickering considers that his photographs show ten stars with composite spectra; of these, five are known to be double. The others are : $\tau$ Persei, $\delta$ Aurigæe, $\delta$ Sagittarii, 3 I Ceti, and $\boldsymbol{\beta}$ Capricorni. Perhaps $\boldsymbol{\beta}$ Lyræ should be added to this list.

In his recent classical work on the rotation of the sun, Dunér has not only determined the solar rotation for the equator but for different parallels of latitude up to $75^{\circ}$. The close accord ance of his results shows that these observations are sufficiently accurate to be discussed with the variation of the solar rotation for different latitudes which had been determined by the older astronomical methods from the observations of the solar spots.

Though I have already spoken incidentally of the invaluable aid which is furnished by photography in some of the applications of the spectroscope to the heavenly bodies, the new power which modern photography has put into the hands of the astronomer is so great, and has led already, within the last few years, to new acquisitions of knowledge of such vast importance, that it is fitting that a few sentences should be specially devoted to this subject.

Photography is no new discovery, being about half a century old; it may excite surprise, and indeed possibly suggest some apathy on the part of astronomers, that though the suggestion of the application of photography to the heavenly bodies dates from the memorable occasion when, in 1839 , Arago, announcing to the Académie des Sciences the great discovery of Niepce and Daguerre, spoke of the possibility of taking pictures of the sun and moon by the new process, yet that it is only within a few years that notable advances in astronomical methods and discovery have been made by its aid.

The explanation is to be found in the comparative unsuitability of the earlier photographic methods for use in the observatory. In justice to the earlier workers in astronomical photography, among whom Bond, De la Rue, J. W. Draper, Rutherfurd, Gould, hold a foremost place, it is needful to state clearly that the recent great successes in astronomical photography are not due to greater skill, nor, to any great extent, to superior instruments, but to the very great advantages which the modern gelatine dry plate possesses for use in the observatory over the methcds of Daguerre, and even over the wet collodion film on glass, which, though a great advance on the silver plate, went but a little way towards putting into the hands of the astronomer a photographic surface adapted fully to his wants.

The modern silver-bromide gelatine plate, except for its grained texture, meets the needs of the astronomer at all points. It possesses extremc sensitiveness; it is always ready for use;

$$
\text { NO. } 1138 \text {, voL. 44] }
$$


it can be placed in any position ; it can be exposed for hours ; lastly, it does not need immediate development, and for this reason can be exposed again to the same object on succeeding nights, so as to make up by several instalments, as the weather may permit, the total time of exposure which is deemed necessary.

Without the assistance of photography, however greatly the resources of genius might overcome the optical and mechanical difficulties of constructing large telescopes, the astronomer would have to depend in the last resource upon his eye. Now we cannct by the force of continued looking bring into view an object too feebly luminous to be seen at the first and keenest moment of vision. But the feeblest light which falls upon the plate is not lost, but is taken in and stored up continuously. Each bour the plate gathers up 3600 times the light-energy which it received during the first second. It is by this power of accumulation that the photographic plate may be said to increase, almost without limit, though not in separating power, the optical means at the disposal of the astronomer for the discovery or the observation of faint objects.

Two principal directions may be pointed out in whichphotography is of great service to the astronomer. It enables him within the comparatively short time of a single exposure to secure permanently with great exactness the relative positions of hundreds or even of thousands of stars, or the minute features of nebula or other objects, or the phenomena of a passing eclipse, a task which by means of the eye and hand could only be accomplished, if done at all, after a very great expenditure of time and labour. Photography puts it in the power of the astronomer to accomplish in the short span of his own life, and so enter into their fruition, great works which olherwise must have been passed on by him as a heritage of labour to succeeding generations.

The second great service which photography renders is not simply an aid to the powers the astronomer already possesses. On the contrary, the plate, by recording light-waves which are both too small and too large to excite vision in the eye, brings him into a new region of knowledge, such as the infra-red and the ultra-violet parts of the spectrum, which must have remained for ever uninown but for artificial help.

The present year will be memorable in astronomical history for the practical beginning of the Photographic Chart and Catalogue of the Heavens, which took their origin in an International Conference $u$ hich met in Paris in 1887 , by the invitation of M. l'Amiral Mouchez, Director of the Paris Observatory.

The richness in stars down to the ninth magnitude of the photographs of the comet of $x 882$ taken at the Cape Observatory under the superintendence of Dr. Gill, and the remarkable star charts of the Brothers Henry which followed two years later, astonished the astronomical world. The great excellence of these photographs, which was due mainly to the superiority of the gelatine plate, suggested to these astronomers a complete map of the sky, and a little later gave birth in the minds of the Paris astronomers to the grand enterprise of an International Chart of the Heavens. The actual beginning of the work this year is in no small degree due to the great energy and tact with which the Director of the Paris Observatory has conducted the initial steps, through the many delicate and difficult questions which have unavoidably presented themselves in an undertaking which depends upon the harmonious working in common of many nationalities, and of no fewer than eighteen observatories in all parts of the world. The three years since I 887 have not been too long for the detailed organization of this work, which has called for several elaborate preliminary investigations on special points in which our knowledge was insufficient, and which have been ably carried out by Profs. Vogel and Bakhuyzen, Dr. Trépied, Dr. Scheiner, Dr. Gill, the Astronomer-Royal, and others. Time also was required for the construction of the new and special instruments.

The decisions of the Conference in their final form provide for the construction of a great pnotographic chart of the heavens with exposures corresponding to forty minutes' exposure at Paris, which it is expected will reach down to stars of about the fourt senth magnitude. As each plate is to be limited to four square degrees, and as each star, to avoid possible errors, is to appear on two plates, over 22,000 photographs will be required. For the more accurate determination of the positions of the stars, a réseau with lines at distances of $5 \mathrm{~mm}$. apart is to be previously impressed by a faint light upon the plate, so that the image of the réseau will appear together with the images of the stars when the plate is developed. This great work will be divided, according to their latitudes, among eighteen observatories provided with similar instruments, though not necessarily constructed by the same maker. Those in the British dominions and at Tacubaya have been constructed by Sir Howard Grubb.

Besides the plates to form the great chart, a second set of plates for a catalogue is to be taken, with a shorter exposure, which will give stars to the eleventh magnitude only. These plates, by a recent decision of the Permanent Committee, are to be pushed on as actively as possible, though as far as may be practicable plates for the chart are to be taken concurrently. Photographing the plates for the catalogue is but the first step in this work, and only supplies the data for the elaborate measurements which have to be made, which are, however, less laborious than would be required for a similar catalogue without the aid of photography.

Already Dr. Gill has nearly brought to conclusion, with the assistance of Prof. Kapteyn, a preliminary photographic survey of the southern heavens.

With an exposure sufficiently long for the faintest stars to impress themselves upon the plate, the accumulating action still goes on for the brighter stars, producing a great enlargement of their images from optical and photographic causes. The question has occupied the attention of many astronomers, whether it is possible to find a law connecting the diameters of these more or less over-exposed images with the relative brightness of the stars themselves. The answer will come out undoubtedly in the affirmative, though at present the empirical formule which have been suggested for this purpose differ from each other. Captain Abney proposes to measure the total photographic action, including density as well as size, by the obstruction which the stellar jmage offers to light.

A further question follows as to the relation which the photographic magnitudes of stars bear to those determined by eye. Visual magnitudes are the physiological expression of the eye's integration of that part of the star's light which extends from the red to the blue. Photographic magnitudes represent the plate's integration of another part of the star's light-namely, from a little below where the power of the eye leaves off in the blue to where the light is cut off by the glass, or is greatly reduced by want of proper corrections when a refracting telescope is used. It is obvious that the two records are taken by different methods in dissimilar units of different parts of the star's light. In the case of certain coloured stars the photographic brightness is very different from the visual brightness; but in all stars, changes, especially of a temporary character, may occur in the photographic or the visual region, unaccompanied by a similar change in the other part of the spectrum. For these reasons it would seem desirable that the two sets of magnitudes should be tabulated independently, and be regarded as supplementary of each other.

The determination of the distances of the fixed stars from the small apparent shift of their positions when viewed from widely separated positions of the earth in its orbit is one of the most refined operations of the observatory. The great precision with which this minute angular quantity - a fraction of a second onlyhas to be measured, is so delicate an operation with the ordinary micrometer, though, indeed, it was with this instrument that the classical observations of Sir Robert Ball were made, that a special instrument, in which the measures are made by moving the two halves of a divided object-glass, known as a heliometer, has been pressed into this service, and quite recently, in the skilful hands of Dr. Gill and Dr. Elkin, has largely increased our knowledge in this direction.

It is obvious that photography might be here of great service, if we could rely upon measurements of photographs of the same stars taken at suitable intervals of time. Prof. Pritchard, to whom is due the honour of having opened this new path, aided by his assistants, has proved by elaborate investigations that measures for parallax may be safely made upon photographic plates, with, of course, the advantages of leisure and repetition; and he has already by this method determined the parallax for twenty-one stars with an accuracy not inferior to that of values previously obtained by purely astronomical methods.

The remarkable successes of astronomical photography, which depend upon the plate's power of accumulation of a very feeble light acting continuously through an exposure of several hours, are worthy to be regarded as a new revelation. The first chapter

No. [ I 38 , VOL. 44] 
opened when, in 1880 , Dr. Henry Draper obtained a picture of the nehula of Orion; but a more important advance was made in 1883 , when Dr. Common, by his photographs, brought to our knowledge details and extensions of this nebula hitherto unknown. A further disclosure took place in 1885 , when the Brothers Henry showed for the first time in great detail the spiral nebulosity issuing from the bright star Maia of the Pleiades, and, shortly afterwards, nebulous streams about the other stars of this group. In $1886, \mathrm{Mr}$. Roberts, by means of a photograph to which three hours' exposure had been given, showed the whole background of this group to be nebulous. In the following year Mr. Roberts more than doubled for us the great extension of the nebular region which surrounds the trapezitum in the constellation of Orion. By his photographs of the great nebula in Andromeda he has shown the true significance of the dark canals which had been seen by the eye. They are in reality spaces between successive rings of bright matter, which appeared nearly straight owing to the inclination in which they lie relatively to us. These bright rings surround an undefined central luminous mass. I have already spoken of this photograph.

Some recent photographs by Mr. Russell show that the great rift in the Milky Way in Argus, which to the eye is void of stars, is in reality uniformly covered with them. Also, quite recently, Mr. George Hale has photographed the prominences by means of a grating, making use of the lines $\mathrm{H}$ and $\mathrm{K}$.

The heavens are richly but very irregularly inwrought with stars, the brighter stars cluster into well known groups upon a background formed of an enlacement of streams and convoluted windings and intertwined spirals of fainter stars, which becomes richer and more intricate in the irregularly rifted zone of the Milky Way.

We, who form part of the emblazonry, can only see the design distorted and confused; here crowded, there scattered, at another place superposed. The groupings due to our position are mixed up with those which are real.

Can we suppose that each Iuminous point has no relation to the others near it than the accidental neighbourship of grains of sand upon the shore, or of particles of the wind-blown dust of the desert? Surely every star, from Sirius and Vega down to each grain of the light-dust of the Milky Way, has its present place in the heavenly pattern from the slow evolving of its past. We see a system of systems, for the broad features of clusters and streams and spiral windings which mark the general design are reproduced in every part. The whole is in motion, each point shifting its position by miles every second, though from the august magnitnde of their distances from us and from each other, it is only by the accumulated movements of years or of generations that some small changes of relative position reveal themselves.

The deciphering of this wonderfully intricate constitution of the heavens will be undoubtedly one of the chief astronomical works of the coming century. The primary task of the sun's motion in space, logether with the motions of the brighter stars, has been already put 'well within our reach by the spectroscopic method of the measurement of star-motions in the line of sight.

From other directions information is accumulating: from photographs of clusters and parts of the Milky Way, by Roberts in this country, Barnard at the Lick Obs ervatory, and Russell at Sydney; from the counting of stars, and the detection of their configurations, by Holden and by Backhouse; from the mapping of the Milky Way by eye, at Parsonstown; from photographs of the spectra of stars, by Pickering at Harvard and in Peru; and from the exact portraiture of the heavens in the great international star chart which begins this year.

I have but touched scme only of the problems of the newer side of astronomy. There are many others which would claim our attention if time permitt $\epsilon$. 'The researches of the Earl of kosse on lunar radiation, and the work on the same subject and on the sun, by Langley. Observations of lunar heat with an instrument of his own invention by Mr. Boys ; and observations of the variation of the moon's heat with its phase by Mr. Frank Very. The discovery of the ultra-violet part of the hydrogen spectrum, not in the laboratory, but from the stars. The confirmation of this spectrum by terrestrial hyorogen in part by $\mathrm{H}$. W. Vogel, and in its all but complete form by Cornu, who found similar series in the ultra-violet spectra of aluminium and thallium. The discovery of a simple formula for the hydrogen

NO. I I 38 , VOL. 44] series by Balmer. 'The important question as' to the numerical spectral relationship of different substances, especially in connec. tion with their chemical properties; and the further question as to the origin of the harmonic and other relations between the lines and the groupings of lines of spectra; on these points contributions during the past year have been made by Rudolf $v$. Kövesligethy, Ames, Hartley, Deslandres, Rydberg, Griinwald, Kayser and Runge, Johnstone Stoney, and others. The remark able employment of interference phenomena by Prof. Michelson for the determination of the size, and distribution of light within them, of the images of objects which when viewed in a telescope subtend an angle less than that subtended by the light-wave at a distance equal to the diameter of the objective. A method applicable not alone to celestial objects, but also to spectral lines, and other questions of molecular physics.

Along the older lines there has not been less activity; by newer methods, by the aid of larger or more accurately constructed instruments, by greater refinement of analysis, knowledge has been increased, especially in precision and minute exactness.

Astronomy, the oldest of the sciences, has more than renewed her youth. At no time in the past has she been so brigbt with unbounded aspirations and hopes. Never were her temples so numerous, nor the crowd of her votaries so great. The British Astronomical Association formed within the year numbers already about 600 members. Happy is the lot of those who are still on the eastern side of life's meridian!

Already, alas ! the original founders of the newer methods are falling out-Kirchhoff, Ångström, D'Arrest, Secchi, Draper, Becquerel; but their places are more than filled; the pace of the race is gaining, but the goal is not and never will be in sight.

Since the time of Newton our knowledge of the phenomena of Nature has wonderfully increased, but man asks, perhaps more earnestly now than in his days, What is the ultimate reality behind the reality of the perceptions? Are they only the pebbles of the beach with which we have been playing? Does not the ocean of ultimate reality and truth lie beyond?

\section{SECTION A}

\section{MATHEMATICS AND PHYSICS.}

Opening AdDress by Prof. Oliver J. Lodge, D.Sc., LL.D., F.R.S., President of the Section.

DURING the past year three or four events call for special mention in an annual deliverance of this kind by a physicist.

One is the Faraday centenary, which was kept in a happy and simple manner by a cosmopolitan gathering in the place so long associated with his work, and by discourses calling attention to the modern development of discoveries made by him.

Another is the decease of the veteran Wilhelm Weber, one of the originators of that absolute system of measurement which, though still ungrasped in its simplicity and completeness by the majority of men engaged in practice, nor even, $X$ fear, wholly understood by some of those engaged in University teaching, has yet done so much, and is destined to do still more, for the unification of physical science, and for a thorough comprehension of its range and its limitations.

A third event of importance during the year is the discovery in America of a binary system of stars, revolving round each other with grotesque haste, and with a proximity to each other such as to render their ordinary optical separation quite impossible. Ideas concerning the future of such systems, if, as seems probable, their revolution period is shorter than their axial period, will readily suggest themselves, in accordance with the principles elaborated by Prof. George Darwin. The subject more properly belongs to our President, but I may parenthetically exclaim at the singular absurdity of the notion which was once propounded by a philosopher, that motion of stars in our line of sight nust for ever remain unknown to us; when the mere time of revolution of a satellite, compared with its distance from its central body, is theoretically sufficient to give us information on this head. As a matter of pedagogy it is convenient to observe that the principle called Doppler's, which is generally known to apply to the periodic disturbances called Light and Sound, applies equally to all periodic occurrences; and that the explanation of anomalies of Jupiter's first satellite by Roemer may be regarded as an instance of Doppler's 
principle. I Any discrepancy between the observed and the cal culated times of revolution of stars round each other can possibly be explained by a relative motion between us and the pair of bodies along the line of sight.

If our text-books clearly recognized this, we should not so often find examination candidates asserting that the apparent time of revolution of a satellite of Jupiter depends on the distance of the earth from that planet, instead of on the speed. I should indeed he sorry to be judged by the performance of my own students, but I fear that many of the less obvious mistakes made by reasonably trained examination candidates are more directly traceable to their teachers than some of us as teachers would like to admit.

The change in the refrangibility of light by reason of the motion of its source, though commonplace enongh now, was at first regarded as too sn all to be ohserved, and one or two attempts directed to detecting the effect of this principle on the spectra of the stars, or sometimes on sunlight reflected by a $45^{\circ}$ mirror into the line of the earth's motion (which is not a possible method), wholly failed. I take pleasure in remembering that this effect was clearly observed for the first time by the gentleman we this year honour as our President; and that it is by this very means that the latest sensational discovery in astronomy of the rapidly revolving twin star $\beta$-Aurigæ, by Prof. Pickering and the staff connected with the Draper Memorial, was made.

The funds for the investigation that led to this result were provided by Mrs. Draper, as a memorial to her late husband and if $\beta$.Aurigæ does not constitute a satisfaciory memorial, $I$ $\mathrm{am}$ at a loss to conceive the kind of tombstone which the relations of a man of science would prefer.

The fourth event to which it behoves me to refer is the practical discovery of a physical method for colour photography. When I say practical I do not mean commercial, nor do I know that it will ever become applicable to the ordinary business of the photographer. Whether it does or not, it is a sound achievement by physical means of a result which the chemical means hitherto tried failed, some think necessarily failed, to produce. I say practical, because already it had been suggested as possible theoretically; and a step toward it, indeed very near it, had been actually made. The first suggestion of the method, so far as I know, was made by Lord Rayleigh in the course of a mathematical paper on the reflection of light, and with reference to some results of Becquerel obtained on a totally different plan. He said in a note that if by normal reflection waves of light were converted into stationary waves, they could shake out silver in strata half a wave length apart, and that such strata would give selective reflection and show iridescence.

The colour of certain crystals of chlorate of potash, described in a precise manner by Sir George Stokes (Proc. Roy. Soc., February 1885), and also the colours of opal and ancient glass, had been elaborately and completely explained by Lord Rayleigh on this theory of a periodic structure (the laminated structure in the case of chlorate of potash being caused by twinning) (Phil. Mag., September I888, pp. 256 and 24I); and he subsequently illus. trated it with sound and a series of muslin disks one behind the other on a set of lazy-tongs. Each membrane reflected an inappreciable amount, but successive equidistant membranes reinforced each other's action, and the entire set reflected distinctly one definite note, of wave-length twice the distance between adjacent muslins. So also with any series of equidistant strata each very slightly reflecting. They should give selective reflection, and the spectrum of their reflected beam should show a single line or narrow band, corresponding to a wave-length twice the distance of the strata apart. ${ }^{2}$

${ }^{2}$ Dr. Huggins has just pointed out to me a perfectly clear statement to the above effect in Professor Tait's little book on Light.

${ }_{2}$ The footnote of Lord Rayleigh on page 158, Phil. Mag., 1887, vol. xxiv. is brief and forcible enough to quote in full:- "A detailed experimental examination of the various cases in which a laminated structure leads to a powerful but highly selected reflection would be of value. The most frequent examples are m.et with in the organic world. It has occurred to me that Becquerel's reproduction of the spectrum in natural colours upon silver plates may perhaps be explicable in this manner. The various parts of the
tilm of subchloride of silver with which the metal is coated may be conceived thlm of subchloride of silver with which the metal is coated may be conceived to be subjected during exposure to stationary luminous waves of nearly definite wave-length, the effect of which might be to impress upon the substance a periodic structure occurring at intervals equal to half the wavelength of light; just as a sensitive flame exposed to stationary sonorous waves is influenced at the loops, but not at the $\mathrm{n}$ des (Phil. Mag., Marcl 1879, p. 153). In this way the operation of any kind of light would be to procuce just such a modification of the film as would cause it to reflect copiously suggestiun, in the hope of soon finding an opportunity of making myself suggestiun, in the hope of soon finding at ,oppd."
experimentally acquainted with the subject.

NO. I I 38 , VOL. 44$]$
Independently of all this, Herr Otto Wiener, imitating Hertz's experiments with ordinary light, in 1889 reflected a beam directly back on itself, and, by interposing a very thin collodion film at extraordinarily oblique incidence, succeeded in the difficult experiment of so magnifying by the cosine of inclination the half wave-length, as to get the silver deposited in strata of visible width, and thus to photograph the interference nodes themselves at the places where they were cut by the plane of the film (Wiedemann's Annalen, vol, xl., I89o).

Then M. Lippmann, using a thicker film, not put obliquely but normal to the light, obtained the strata within the thickness of the film itself-hundreds of layers; and so, employing incidence light of definite wave-length, was able to produce a stratified deposit, which reflected back at appropriate incidences the same wave-length as produced it ; thus reproducing, of course, the definite colour.

It is probable that the silver is first shaken out at the ventral segments, but that the strata so formed are thick and blurry. I conjecture that by over-exposure this deposit is nearly all mopped up again, traces being left only at the nodes, where the action is very feeble and takes a long time to occur; but that these residual strata, being fairly sharp and definite, will be likely to give much better effects. And so I suppose that these are what are actually effective in obtaining M. Lippmann's very interesting, though not yet practically useful, result.

I now leave the retrospect of what has been done, although many other topics might usefully detain us, and I proceed to glance forward at the progress ahead and at the means we have for effectively grappling with our due share of it.

There is a subject which has long been in my mind, and which I determined to bring forward whenever I had a cathedral opportunity of doing so ; and now, if ever, is a suitable occasion. It is to call attention to the fact that the further progress of physical science in the somewhat haphazard and amateur fashion in which it has been hitherto pursued in this country is becoming increasingly difficult, and that the quantitative portion especially should be undertaken in a permanent and publicly-supported physical laboratory on a large scale. If such an establishment were to weaken the sinews of private enterprise and individual research it should be strenuously opposed ; but, in my opinion, it would have the opposite effect, by relieving the private worker of much which he can only with great difficulty, sacrifice, and expense, undertake. To illustrate more precisely what I mean, it is sufficient to recall the case of astronomy. The amateur astronomer has much work lying ready to his hand, aud he grapples with it manfully. To him is left the striking out of new lines and the guerilla warfare of science. Skirmishing and brilliant cavalry evolutions are his natural field, he should not be called upon to take part in the general infantry advance. It is wasting his energies, and he could not do it in the long run well. What, for instance, would have been the state of astronometry-the nautical almanac department of astronomy-without the consecutive and systematic work of the National Observatory at Greenwich? It may be that some enthusiastic amateurs would have devoted their lives to this routine kind of work, and here at one time and there at another a series of accurate observations would have been kept for several years. Pur ued in that way, however, not only would the effort be spasmodic and temporary, but the energy and enthusiasm of those amateurs would have been diverted from the pioneering more suited to them, and have been cramped in the groove of routine, eminently adapted to a permanent official staff, but not wholesome for an individual.

Long-continued consecutive observations may be made by a leader of science, as funclions may be tabulated by an eminent mathematician; but if the work can be done almost equally well (some would say better) by a professional observer or computator, how great an economy results.

Now all this applies equally to physics. The ohm has been determined with 4 -figure, perhaps with 5 -figure, accuracy; but think of the list of eminent men to whose severe personal labour we owe this result, and ask if the spoil is worth the cost. Perhaps in this case it is, as a specimen of a well-conducted determination. We must have a few specimens, and our leaders must show us the way to do things. But let us not continue to use them for such purposes much longer. The quest of the fifth or sixth decimal is a very legitimate, and may become a very absorbing, quest, but there are plenty of the rank and file who can undertake it if properly generalled and led : not as isolated individuals, but as workers in a National Laboratory under a competent head and a governing committee. By this means work far 
greater in quantity, and in the long run more exact in quality, can be turned out, by patient and conscientious labour without much genius, by the gradual improvement of instrumental means, by the skill acquired by practice, and by the steady drudgery of routine. Paris has long had one form of such an institution, in the Conservatoire des Arts et Métiers, and has been able to impose the metric system on the civilised world in consequence. It can also point to the classical determinations of Regnault as the fruits of just such a system. Berlin is now starting a similar or a more ambitious scheme for a permanent national physical institute. Is it not time that England, who in physical science, I venture to think, may in some sort claim a leading place, should be thinking of starting the same movement?

The Meteorological and Magnetic Observatory at Kew (in the inauguration of which this Association took so large a part) is a step, and much useful quantitative work is done there. The new Flectric Standardizing Laboratory of the Board of Trade is another and, in some respects perhaps, a still closer appproximation to the kind of thing I advocate. But what I want to see is a much larger establishment erected on the most suitable site, limited by no speciality of aim nor by the demands of the commercial world, furnished with all appropriate appliances, to be amended and added to as time goes on and experience grows, and invested with all the dignity and permanence of a national institution : a Physical Observatory, in fact, precisely comparable to the Greenwich Observatory, and aiming at the very highest quantitative work in all departments of physical science. That the arts would be benefited may be assumed without proof. It is largely the necessity of engineers that has inspired the amount of accuracy in electrical matters already attained. The work and appliances of the mechanical engineer eclipse the present achievements of the physicist in point of accuracy, and it is by the aid of the mechanician and optician that precision even in astronomy has reached so high a stage. There is no reason why physical determinations should be conducted in an amateur fashion, with com. paratively imperfect instruments, as at present they moctly are. Discoveries lie along the path of extreme accuracy, and they will turn up in the most unexpected way. The aberration of light would not have been discovered had not Bradley been able to measure to less than I part in $\mathrm{IO}, 000$; and what a brilliant and momentous discovery it was! He was aiming at the detection of stellar parallax, but the finite velocity of light was a bigger discovery than any parallax. This is the type of result which sometimes lurks in the fifth decimal, and which confers upon it an importance beside which the demands of $m \in n$ who wish to serve the taste and the pocliet of the British public sink into insignificance.

In a National Observatory accuracy should be the one great end : the utmost accuracy in every determination that is decided on and made. Only one thing should be more thought of than the fifth significant figure, and that is the sixth. The consequences flowing from the results may safely be left; such as are not obvious at once will distil themselves out in time. And the great army of outside physicists, assured of the good work being done at headquarters, will (to speak again in astronomical parable) cease from peddling with taking transits or altitudes, and will be free to discover comets, to invent the spectroscope, to watch solar phenomena, to chemically analyse the stars, to devise celestial photography, and to elaborate still more celestial theories; all of which novelties in their maturity may be handed over to the National Observatory, to be henceforth incorporated with, and made part of, its routine life; leaving the advance guard and skirmishers free to explore fresh territory, secure in the knowledge that what they have acquired will be properly surveyed, mapped, and utilised, without further attention from them. As to the practical applications, they may in any case be left to take care of themselves. The instinct of humanity in this direction, and the so-called solid gains associated with practical achievements, will always secure a sufficient number of acute and energetic workers to turn the new territory into arable land and pasture adapted to the demands of the average man. The labour of the agriculturist in rendering soil fertile is, of course, beyond praise; but it is not the work of the pioneer. As Mr. Huxley eloquently put it, when contrasting the application of science with the advance of science itself, speaking of the things of commercial value which the physical philosopher sometimes discovers :- "Great is the rejoicing of those who are benefited thereby, and, for the moment, science is the Diana of all the craftsmen. But even while the cries of jubilation resound, and this flotsam and jetsam of the tide of investigation is being turned into the wages of workmen and the wealth of capitalists, the crest of the wave of scientific investigation is far away on its course over the illimitable ocean of the unknown."

I have spoken of the work of the National Laboratory as devoted to accuracy. It is hardly necessary to say that it will be also the natural custodian of our standards, in a state fit for use and for comparison with copies sent to be certufied. Else perhaps some day our standard ohm may be buried in a brick wall at Westminster, and no one living may be able to recall precisely where it is.

But, in addition to these main functions, there is another, equally important with them, to which I must briefly refer. There are many experiments which cannot possibly be conducted by an individual, because forty or fifty years is not long enough for them. Secular experiments on the properties of materialsthe elasticity of metals, for instance ; the effect of time on molecular arrangement ; the influence of long exposure to light, or to heat, or to mechanical vibration, or to other physical agents.

Does the permeability of soft iron decay with age, by reason of the gradual cessation of its Amperian currents? Do gases cool themselves when adiabatically preserved, by reason of imperfect elasticity or too many degrees of freedom of their molecules? Unlikely, but not impossible. Do thermo-electric properties alter with time? And a multitude of other experiments which appear specially applicable to substances in the solid state-a state which is more complicated, and has been less investigated, than either the liquid or the gaseous : a state in which time and past history play an important part.

Whichever of these long researches requires to be entered on, a national laboratory, with permanent traditions and a continuous life, is undoubtedly the only appropriate place. At such a place as Glasgow the exceptional magnitude of a present occupant may indeed inspire sufficient piety in a successor to secure the continuance of what has been there begun; but in most college laboratories, under conditions of migration, interregnum, and a new régime, continuity of investigation is hopeless.

I have at any rate said enough to indicate the kind of work for which the establishment of a well-furnished laboratory with fully equipped staff is desirable, and I do not think that we, as a nation, shall be taking our proper share of the highest scien. tific work of the world until such an institution is started on its career.

There is only one evil which, so far as I can see, is to be feared from it: if ever it were allowed to impose on outside workers as a central authority, from which infallible dicta were issued, it would be an evil so great that no amount of good work carried on by it could be pleaded as sufficient mitigation.

If ever by evil chance such an attitude were attempted, it must rest with the workers of the future to see that they permit no such shackles; for if they are not competent to be independent, and to contem the voice of authority speaking as mere authority, if their only safeguard lies in the absence of necessity for struggle and effort, they cannot long hope to escape from the futility which surely awaits them in other directions.

I am thus led to take a wider range, and, leaving temporary and special considerations, to speak of a topic which is as yet beyond the pale of scientific orthodoxy, and which I might, more wisely, leave lying by the roadside. I will, however, take the risk of introducing a rather ill-favoured and disreputable looking stranger to your consideration, in the belief-I might say, in the assured conviction-that he is not all scamp, and that his present condition is as much due to our long-continued neglect as to any inherent incapacity for improvement in the subject.

I wish, however, strenuously to guard against its being supposed that this Association, in its corporate capacity, lends its countenance to, or looks with any favour on, the outcast. What I have to say-and after all, it will not be much-must rest on my own responsibility. I should be very sorry for any adventitious weight to attach to my observations on forbidden topics from the accident of their being delivered from this chair. The objection at which I have now hinted is the only one that seems to me to have any just weight, and on all other counts I am willing to incur such amount of opprobrium as naturally attaches to those who enter on a region where the fires of controversy are not extinct, and in which it is quite impossible, as well as undesirable, for everyone to think alike.

It is but a platitude to say that our clear and conscious aim should always be truth, and that no lower or meaner standard

NO. I I 38 , vOL. 44] 
should ever be allowed to obtrude itself before us. Our ancestors fought hard and suffered much for the privilege of free and open inquiry, for the right of conducting investigation untrammelled by prejudice and foregone conclusions, and they were ready to examine into any phenomenon which presented itself. This attitude of mind is perhaps necessarily less prominent now, when so much knowledge has been gained, and when the labours of many individuals may be rightly directed entirely to its systematization and a study of its inner ramifications; but it would be a great pity if a too absorbed attention to what has already been acquired, and to the fringe of territory lying immediately adjacent thereto, were to end in our losing the power of raising our eyes and receiving evidence of a totally fresh kind, of perceiving the existence of regions into which the same processes of inquiry as had proved so fruitful might be extended, with results at present incalculable and perhaps wholly unexpected. I myself think that the ordinary processes of observation and experiment are establishing the existence of such a region; that, in fact, they have already established the truth of some phenomena not at present contemplated by science, and to which the orthodox man shuts his ears.

For instance, there is the question whether it has or has not been established by direct experiment that a method of communication exists between mind and mind irrespective of the ordinary channels of consciousness and the known organs of sense, and, if so, what is the process. It can hardly be through some unknown sense organ, but it may be by some direct physical influence on the ether, or it may be in some still more subtle manner. Of the process $I$ as yet know nothing. For brevity it may be styled "thought-transference," though the name may turn out to be an unsuitable one after further investigation. Further investigation is just what is wanted. No one can expect othes to accept his word for an entirely new fact, except as establishing a prima facie case for investigation.

But I am only now taking this as an instance of what I mean; whether it be a truth or a fiction, there is not, I suppose, one of the recognized scientific societies who would receive a paper on the subject. ${ }^{1}$ There are individual scientific men who have investigated these matters for themselves; there are others who are willing to receive evidence, who hold their minds open and their judgment in suspense ; but these are only individuals. The great majority, I think I am right in saying, feel active hostility to these researches and a determined opposition to the reception or discussion of evidence. And they feel this confirmed scepticism, as they call it, not after prolonged investigation, for then it might be justified, but sometimes after no investigation at all. A few tricks at a public performance, or the artifices of some impostor, and they decline to consider the matter further.

That individuals should take this line is, however, natural enough ; they may be otherwise occupied and interested. Everybody is by no means bound to investigate everything; though, indeed, it is customary in most fields of knowledge for those who have kept aloof from a particular inquiry to defer in moderation to those who have conducted it, without feeling themselves called upon to express an opinion. Some there are, no doubt, who consider that they have given sufficient time and attention to the subject with only negative results. Their evidence is, of course, important; but plainly, negative evidence should be of immense bulk and weight before it can outweigh even a moderate amount of positive evidence. However, it is not of the action of individuals that I wish to speak, it is of the attitude to be adopted by scientific bodies in their corporate capacity; and for a corporate body of men of science, inheritors of the hard-won tradition of free and fearless inquiry into the facts of nature untrammelled by prejudice, for any such body to decline to receive evidence laboriously attained and discreetly and inoffensively presented by observers of accepted competency in other branches, would be, if ever actually done and persisted in, a terrible throwing away of their prerogative, and an imitation of the errors of a school of thought against which the struggle was at one time severe.

In the early days of the Copernican theory, Galileo for some years refrained from teaching it, though fully believing its truth because he considered that he had better get more fully settled in his University chair before evoking the storm of controversy which the abandonment of the Ptolemaic system would arouse. The same thing in very minor degree is going on to-day. I know of men who hesitate to avow interest in these new investigation

I This, however, is mere conjecture. I am not aware that the experiment has been tried.

$$
\text { NO. I I } 38 \text {, VOL. 44] }
$$

(I do not mean credence-the time is too early for avowing credence in any but the most rudimentary and definitely ascertained facts-but hesitate to avow interest) until they have settled down more securely and made a name for themselves in other lines. Caution and slow progress are extremely necessary; fear of avowing interest or of examining into unortbodox facts is, I venture to say, not in accordance with the highest traditions of the scientific attitude.

We are, I suppose, to some extent afraid of each other, but we are still more afraid of ourselves. We have great respeot for the opinions of our elders and superiors; we find the matter distasteful to them, so we are silent. We have, moreover, a righteous mistrust of our own powers and knowledge ; we perceive that it is a wide region extending into several already cultivated branches of science, that a many-sided and highly-trained mind is necessary adequately to cope with all its ramifications, that in the absence of strict inquiry imposture has been rampant in some portions of it for centuries, and that unless we are preternaturally careful we may get led into quagmires if we venture on it at all.

Now let me be more definite, and try to state what this field is, the exploration of which is regarded as so dangerous. I might call it the borderland of physics and psychology. I might call it the connection between life and energy; or the connection between mind and matter. It is an intermediate region, bounded on the north by psychology, on the south by physics, on the east by physiology, and on the west by pathology and medicine. An occasional psychologist has groped down into it and become a metaphysician. An occasional physicist has wandered up into it and lost his base, to the horror of his quondam brethren. Biologists mostly look at it askance, or deny its existence. A few medical practi. tioners, after long maintenance of a similar attitude, have begun to annex a portion of its western frontier. The whole region seems to be inhabited mainly by savages, many of them, so far as we can judge from a distance, given to gross superstition. It may, for all I know, have been hastily traversed, and rudely surveyed by a few clear-eyed travellers; but their legends concerning it are not very credible, certainly are not believed.

Why not leave it to the metaphysicians? I say it has been left to them long enough. They have explored it with insulficient equipment. The physical knowledge of the great philosophers has been necessarily scanty. Men of genius they were, and their writings may, when interpreted, mean mucb. But to us, as physicists, they are unsatisfactory; their methods are not our methods. They may be said to have floated a balloon over the region with a looking.glass attached, in which they have caught queer and fragmentary glimpses. They may have seen more than we give them credit for, but they appear to have guessed far more than they saw.

Our method is different. We prefer to creep slowly from our base of physical knowledge, to engineer carefully as we go, establishing forts, making roads, and thoroughly exploring the country; making a progress very slow, but very lasting. The psychologists from their side may meet us. I hope they will; but one or other of us ought to begin.

A vulnerable spot on our side seems to be the connection between life and energy. The conservation of energy has been so long established as to bave become a commonplace. The relation of life to energy is not understood. Life is not energy, and the death of an animal affects the amount of energy no whit; yet a live animal exerts control over energy which a dead one cannot. Life is a guiding or directing principle, disturbing to the physical world but not yet given a place in the scheme of physics. The transfer of energy is accounted for by the performance of work; the guidance of energy needs no work, but demands force only. What is force? and how can living beings exert it in the way they do? An automaton worked by preceding conditions-that is, by the past-say the materialists. Are w'e so sure that they are not worked by the future too? In other words, that the totality of things, by which every one must admit that actions are guided, includes the future as well as the past, and that to attem $t$ to deduce those actions from the past only will prove impossible. ${ }^{r}$ In some way matter can be moved, guided, disturbed, by the agency of living beings ; in some way there is a control, a directing-agency active, and events are caused at its choice and will that would not otherwise happen. 1 The expression "controlled by the future" I first heard in a conversa
tion with G. F. Fitzgerald, who seemed to consider it applicable to al tion with G. F. Fitzgerald, 
A luminous and helpful idea is that time is but a relative mode of regarding things ; we progress through phenomena at a certain defin te pace, and this subjective advance we interpret in an objective manner, as if events necessarily happened in this order and at this precise rate. But that may be only one mode of regarding them. The events may be in some sense existent always, both past and futurè, and it may be we who are arriving at them, not they which are happening. The analogy of a traveller in a railway irain is useful. If he could never leave the train $\mathrm{n}$ )r alter its pace, he would probably consider the landscapes as necessarily successive, and be unable to conceive their co-existence.

The analogy of a solid cut into sections is closer. We recognise the universe in sections, and each section we call the present. It is like the string of slices cut by a misrotome; it is our way of studying the whole. But we may err in supposing that the body only exists in the slices which pass before our microscope in regular order and succession.

We perceive, therefore, a possible fourth dimensional aspect about time, the inexorableness of whose flow may be a natural part of o..r present limitations. And if once we grasp the idea that past and future may be actually existing, we can recognise that they may have a controlling influence on all present action, and the two together may constitute "the higher plane," or the totality of things, after which, as it seems to me, we are impelled to seek, in connection with the directing of force or determinism, and the action of living beings consciously directed to a definite and preconceived end.

Inanimate matter is controlled by the vis a tergo; it is operated on solely by the past. ${ }^{1}$ Given certain conditions, and the effect in due time follows. Attempts have been made to apply the same principle to living and conscious beings, but without much succe s. These seem to work for an object, even if it be the mere seeking for food; they are controlled by the idea of something not yet palpable. Given certain conditions, and their action cannot certainly be predicted ; they have a sense of option and free will. Either their actions are really arbitrary and indeterminate - which is highly improbable - or they are controlled by the future as well as by the past. Imagine beings thus controlled: automata you may still call them, but they will be living automata, and will exhibit all the characteristics of live creatures. Moreover, if they have a merely experiential know'edge, necessarily limited by memory and bounded by the past, they will be unable to predict each other's actions with any certainty, because the whole of the data are not before them. May not a clearer apprehension of the meaning of life and will and determinism be gradually reached in some such direction as this?

By what means is force exerted, and what, definitely, is force? I can hardly put the question here and now so as to be intelligible, except to those who have approached and thought over the same difficulties; but I venture to say that there is here something not provided for in the orthodox scheme of physics; that modern physics is not complete, and that a line of possible advance lies in this direction.

I might go further. Given that force can be exerted by an act of will, do we understand the mechanism by which this is done? And if there is a gap in our knowledge between the conscious idea of a motion and the liberation of muscular energy needed to accomplish it, how do we know that a body may not be moved without ordinary material contact by an act of will? I have no evidence that such a thing is possible. I have tried once or twice to observe its asserted occurrence, and failed to get anything that satisfied me. Others may have been more fortunate. In any case, I hold that we require more knowledge before we can deny the possibility. If the conservation of energy were upset by the process, we shonld have grounds for denying it ; but nothing that we know is upset by the discovery of a novel medium of communication, perhaps some more immediate action through the ether. It is no use theorising; it is unwise to decline to examine phenomena because we feel too sure of their impossibility. We ought to know the universe very thoroughly and completely before we take up that attitude.

Again, it is familiar that a thought may be excited in the brain of another person, transferred thither from our brain, by pulling a suitable trigger; by liberating energy in the form of sound, for instance, or by the mechanical act of

I This is, of course, not assertion, but suggestion. It may be erroneous to draw any such distinction between animate and inanimate. writing, or in other ways. A prearranged code called language, and a material medium of communication, are the recognised methods. May there not also be an immaterial (perhaps an ethereal) medium of communication? Is it possible that an idea can be transferred from one person to another by a process such as we have not yet grown accustomed to, and know practically nothing about? In this case I have evidence. I assert that $\mathrm{I}$ have seen it done; and am perfectly convinced of the fact. Many others are satisfied of the truth of it too. Why must we speak of it with bated breath, as of a thing of which we are ashamed? What right have we to be ashamed of a truth?

And after all, when we have grown accustomed to it, it will not seem altogether strange. It is, perhaps, a natural consequence of the community of life or family relationship running through all living beings. The transmision of life may be likened in some ways to the transmission of magnetism, and all magnets are sympathetically connected, so that if suitably suspended a vibration from one disturbs others, even though they be distant ninety-two million miles.

It is sometimes objected that, granting thought-transference or telepathy to be a fact, it belongs more especially to lower forms of life, and that as the cerebral hemispheres develop we become independent of it; that what we notice is the relic of a decaying faculty, not the germ of a new and fruitful sense; and that progress is not to be made by studying or attending to it. It may be that it is an immature mode of communication, adapted to lower stages of consciousness than ours, but how much can we not learn by studying immature stages? As well might the objection be urged against a study of embryology. It may, on the other hand, be an indication of a higher mode of communication, which shall survive our temporary connection with ordinary matter.

I have spoken of the apparently direct action of mind on mind, and of a possible action of mind on matter. But the whole region is unexplored territory, and it is conceivable that matter may react on mind in a way we can at present only dimly imagine. In fact, the barrier between the two may gradually melt away, as so many other barriers have done, and we may end in a wider perception of the unity of nature, such as philosophers have already dreamt of.

I care not what the end may be. I do care that the inquiry shall be conducted by us, and that we shall be free from the disgrace of jogging along accustomed roads, leaving to outsiders the work, the ridicule, and the gratification, of unfolding a new region to unwilling eyes.

It may be held that such investigations are not physical and do not concern us. We cannot tell without trying. In that I trust my instinct: I believe there is something in this region which does concern us as physicists. It may concern other sciences too. It must, one would suppose, some day concern biology ; but with that I have nothing to do. Biologists have their region, we have ours, and there is no need for us to hang back from an investigation because they do. Our own science, of Physics or Natural Philosophy in its widest sense, is the King of the Sciences, and it is for us to lead, not to follow.

And I say, have faith in the Intelligibility of the universe. Intelligibility has been the great creed in the strength of which all intellectual advance has been attempted, and all scientific progress made.

At first things always look mysterious. A comet, lightning, the aurora, the rainbow - all strange anomalous mysterious apparitions. But scrutinized in the dry light of science, their relationship with other better-known things becomes apparent. They cease to be anomalous; and though a certain mystery necessarily remains, it is no more a property peculiar to them, it is shared by the commonest objects of daily life.

The operations of a chemist, again, if conducted in a haphazard manner, would be an indescribable medley of effervescences, precipitations, changes in colour and in substance; but, guided by a thread of theory running through them the processes fall into a series, they all become fairly intelligible, and any explosion or catastrophe that may occur is capable of explanation too.

Now I say that the doctrine of ultimate intelligibility should be pressed into other departments also. At present we hang back from whole regions of inquiry, and say they are not for us. A few we are beginning to grapple with. The nature of disea e is yielding to scrutiny with fruitful result ; the mental aberrations and abnormalities of hypnotism, duplex personality, and allied

NO. II 38 , vOL. 44] 
phenomena, are now at last being taken under the wing of science after long ridicule and contempt. The phenomenon of crime, the scientific meaning and justification of altruism, and other matters relating to life and conduct, are beginning, or perhaps are barely yet beginning, to show a vulnerable front over which the forces of science may pour.

Facts so strange that they have been called miraculous are now no longer regarded as entirely incredible. All occurrences seem reasonable when contemplated from the right point of view, and some are believed in which in their essence are still quite marvellous. Apply warmth for a given period to a sparrow's egg, and what result could be more incredible or magical if now discovered for the first time. The possibilities of the universe are as infinite as is its physical extent. Why should we grope with our eyes always downward, and deny the possibility of everything out of our accustomed beat.

If there is a puzzle about free-will, let it be attacked; puzzles mean a state of half-knowledge; by the time we can grasp something more approximating to the totality of things the paradoxity of paradoxes drops away and becomes unrecognizable. I seem to myself to catch glimpses of clues to many of these old questions, and I urge that we should trust consciousness, which has led us thus far; should shrink from no problem when the time seems ripe for an attack upon it, and should not hesitate to press investigation, and ascertain the laws of even the most recondite problems of life and mind.

What we know is as nothing to that which remains to he known. This is sometimes said as a truism; sometimes it is half doubted. To me it seems the most literal truth, and that if we narrow our view to already half-conquered territory only, we shall he false to the men who won our freedom, and treasonable to the bighest claims of science.

I must now return to the work of this Section, from which I have apparently wandered rather far afield, further than is customary-perhaps further than is desirable. But I hold that occasionally a wide outlook is wholesome, and that without such occasional survey, the rigid attention to detail and minute scrutiny of every little fact, which are so entirely admirable and are so rightly here fostered, are apt to become unhealthily dull and monotonous. Our life-works is concerned with the rigid framework of facts, the skeleton or outline map of the universe: and, though it is well for us occasionally to remember that the texture and colour and beauty which we habitually ignore are not therefore in the slightest degree non-existent, yet it is safest speedily to return to our base and continue the slow and laborious march with which we are familiar and which experience has justified. It is because I imagine that such sy:tematic advance is now beginning to be possible in a fresh and unexpected direction that I have attempted to direct jour attention to a subject which, if my progniostications are correct, may turn out to be one of special and peculiar interest to humanity.

\section{THE LATE PROF. MARTIN DUNCAN, F.R.S.}

$W^{T E}$ have already announced the death of this wellknown geologist; and now give a brief account of his services to science.

As a Fellow of the Royal, Linnean, Geological, and Microscopical Societies, and for some time President of the two last-named of these, it goes without saying that his attainments were of no mean order. Educated for the medical profession at King's College, London, he matriculated at the London University in I84 I, taking honours in anatomy and physiology in 1844 , and the degree of Bachelor of Medicine in I 846 , in which year also he qualified as a Member of the Royal College of Surgeons. His early life was passed at Rochester with Dr. Martin, and at Colchester, where he was in practice for some years, and where he so won the esteem of all who knew him that he was elected Mayor of that city. Fascinated with the study of geology, and impressed with the idea that to make any mark in the scientific world a man should take up some spécialité, he not only obtained a broad grasp of his favourite subject, but devoted himself especially to a study of fossil corals and echinoderms, on which subjects at intervals he published numerous valuable memoirs. Indeed, for many years, and up to

$$
\text { NC. I I } 38 \text {, VOL. } 44]
$$

within a comparatively short period of his death, he continued to work at his special subject, and contributed many important papers to the Annals and Magazine of Natural History, the Journal of the Geological Society, the Geological Magazine, Quarterly Foumal of Microscopical Science, the Philosophical Transactions and Proceedings of the Royal Society, the Proceedings and Transactions of the Zoological Society, and the Journal of the Linnean Society.

He soon found that residence out of London, away from scientific societies and important works of reference, was a great obstacle to work, and that if he was to make any real progress with his special studies it was absolutely necessary for him to seek some appointment in the metropolis. Fortunately for him, as it happened, the Chair of Geology at King's College became vacant, and he was appointed to fill it. This at once gave him the opportunity he had solong hoped for, and the preparation of his lectures proceeded side by side with much useful work, which, by degrees, he found time to publish. Such, for example, was his account of the Madreporaria collected during the expedition of H.M.S. Porcupine, which appeared in the Transactions of the Zoological Society (Part I, vol. viii. p. 303, \&c., and Part 2, vol. x. p. 235, \&c.) ; his description of deep-sea and litoral corals from the Atlantic and Indian Oceans (Proc. Zool. Soc., 1876, p. $428, \&$ c.) ; and his important revision of the Echinoidea, printed in the Journal of the Linnean Society, of which it occupied four numbers.

This was all strictly scientific work, but by no means represented all that he accomplished. As a popular exponent of the teaching of geology and zoology, especially in regard to the lower forms of life, he published many excellent articles which were designed to awaken an interest in subjects little investigated, though well worthy of attention.

Lucidly written and full of facts, these articles were at once instructive and suggestive, and from a teachers' point of view did more to educate youthful naturalists and encourage research than any of his more scientific papers, which, being of a more technical character, were less acceptable to the majority of readers because less intelligible to them.

Of this class were his articles on "Corals and their Polypes" (Intellectual Observer, I869, pp. 81-9I, 24I -50, with two coloured plates); "Studies amongst Amœbæ" (Popular Science Review, I877, with two plates), and "Notes on the Ophiurans, or the Sand and Brittle Stars" (Popular Science Review, I878, with a plate).

His attention, however, was not confined to invertebrate zoology or geology. In 1878 he commenced the publication, in six volumes quarto, of a popular " Natural History," which had the merit of being written by a number of able specialists upon a comprehensive plan. under his direction, and, while taking upon himself the laborious duties of editor-in-chief, he contributed many of the sections himself. Thus, while securing the cooperation of such well-known zoologists as the late Prof W. K. Parker, the late Mr. Dallas, Prof. Seeley, Prof. Boyd Dawkins, Dr. H. Woodward, Dr. Murie, Mr. H. W. Bates, and Mr. R. B. Sharpe, he himself undertook the preparation of the articles on Apes and Monkeys, Lemurs (part), Edentata, Marsupialia, Reptilia, and Am. phibia. He also wrote the introduction to the Invertebrata, and the articles Vermes, Zoophytes, and Infusoria which appeared in the last volume, published in 1883 .

For an excellent summary of marine zoology, in which the appearance, structure, and habits of such animals and plants as may be found upon our coasts are well described, the reader may be referred to a little volume by Dr. Duncan, entitled "The Sea-shore." It forms one of a series of "Natural History Rambles," issued a few years since by the Society for Promoting Christian Knowledge, ard, for the amount of information which it 